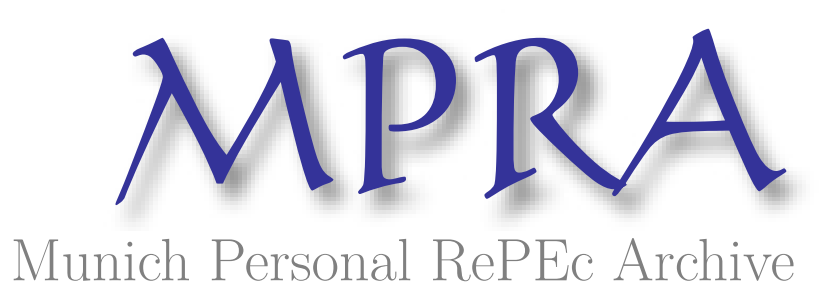

\title{
Linking Reputations through Umbrella Branding
}

Miklos-Thal, Jeanine

2008

Online at https://mpra.ub.uni-muenchen.de/26853/

MPRA Paper No. 26853, posted 19 Nov 2010 16:42 UTC 


\title{
Linking Reputations through Umbrella Branding
}

\author{
Jeanine Miklós-Thal*
}

November 4, 2010

\begin{abstract}
This paper develops a theory of umbrella branding as a way to link the reputations of otherwise unrelated products. My analysis predicts that umbrella branding can credibly signal positive correlation between the qualities of the included products to consumers, but cannot certify high quality or signal negative quality correlation. Moreover, whenever umbrella branding signals perfect positive quality correlation, firms that already sell a high (low) quality product have stronger (weaker) incentives to invest in developing another high quality product than new entrants.
\end{abstract}

Keywords: reputation, umbrella branding, brand extensions, signaling

JEL classification codes: L14, L15, M31

*William E. Simon Graduate School of Business Administration, University of Rochester, Carol Simon Hall 3-141, Rochester, New York 14627, email: jeanine.miklos-thal@Simon.Rochester.edu, phone: 585-276-5166. 


\section{Introduction}

Umbrella branding, the practice of selling several products under the same brand name, is widespread. Some umbrella brands sell related products, e.g., Sony sells flat screen televisions, flat screen monitors, and laptop computers. Others sell products in unrelated categories, e.g., Virgin sells music disks, air travel, cola drinks, and financial services.

A commonly advanced rationale for umbrella branding is that it allows firms to leverage the reputation attached to a brand name (Kapferer 1997; Aaker 2004). Umbrella branding helps firms with strong brands to successfully introduce new products by convincing consumers that new and existing products are of similar quality. Empirical and experimental studies confirm that consumers' quality perceptions of a product are correlated with their evaluations of other products sold under the same umbrella brand. Using scanner panel data of toothpaste and toothbrush sales, Erdem (1998) estimates a correlation between consumers' prior quality perceptions of two umbrella branded products of 0.88. ${ }^{1}$ Sullivan (1990) finds that an alleged sudden-acceleration defect of the Audi 4000 model had significant negative effects on the demands for other models sold under the Audi brand. In a secondary analysis of eight experimental datasets including the one in Aaker and Keller's (1990) seminal study on the question, Bottomley and Holden (2001) find that the perceived quality of the parent brand has a significant effect on how consumers evaluate a brand extension.

One potential explanation for correlated perceptions is that a firm's skill level or other key inputs determine the quality of all products it manufactures and umbrella branding informs consumers that products originate from the same manufacturer. An alternative explanation, which will be the focus of this paper, is that firms have incentives to only employ umbrella brands for products that are similar in terms of quality. Correlation hence arises endogenously as a result of firms' branding decisions.

Endogenous quality correlation is relevant because technological quality correlation due to the use of a common input seems unrealistic in many situations. First, some umbrella branded products are manufactured by different firms. ${ }^{2}$ The AT\&T brand for example used to be licensed to VTech

\footnotetext{
${ }^{1}$ Using the same dataset, Erdem and Winer (1999) find further evidence of inter-category correlation of (multiple) attribute-perceptions for umbrella brands, while Erdem and Sun (2002) show that advertising has an uncertaintyreducing role across categories for umbrella brands.

${ }^{2}$ Short of being manufactured by different firms, some umbrella branded products are manufactured in different factories located in different countries. Many piano brands for instance manufacture their cheaper models in China, while their higher-end models are manufactured in Japan.
} 
for telephone sets and to Verbatim for blank media. Second, there are many brands that have been extended into distant product categories (see Klink and Smith 2001), and evidence from marketing suggests that even in such situations consumers tend to perceive quality links between umbrella branded products (see Swaminathan, Fox, and Reddy 2001; Bottomley and Holden 2001). Third, even products in related categories that are manufactured by the same firm do not always have similar product features and qualities. Only automatic cars can experience sudden acceleration, for example, but after the Audi incident mentioned above negative feedback effects also caused a significant fall in demand for the Audi Quattro that was only available with standard transmission (see Sullian 1990). Fourth and maybe most importantly, technological quality correlation makes only partial sense if we think about quality as the result of investments in product development and choices by the firm. While some firms may simply lack the skills to develop and produce high-quality products, firms that possess the required skills are usually also able to produce low quality and can save costs by doing so. Hence, skill alone is insufficient to explain why products manufactured by the same firm should share the same high quality.

This paper analyzes whether and when umbrella branding can convince rational consumers that products are likely to be of similar or identical quality, even in the absence of technological quality correlation. The model is based on an information asymmetry between firms and consumers. Firms know the qualities of their products, whereas consumers learn about quality over time through observations of product performance, which are imperfect signals of quality. Product qualities are either exogenously given or determined by firms' pre-launch investments in product development.

Since firms can condition their branding decisions on qualities, umbrella branding can convey information to consumers even in the absence of any technological quality correlation. First, the umbrella branding decision itself may influence consumers' beliefs about qualities; umbrella branding has signaling effects in this case. Second, umbrella branding leads to feedback effects whenever consumers believe that the qualities of the included products are correlated. In the case of positive quality correlation, the success (failure) of an umbrella branded product has a positive (negative) feedback effect on consumers' belief about the quality of the other product sold under the same brand (for evidence of such feedback effects, see Sullivan 1990; John, Loken and Joiner 1998). I analyze the interplay of these effects in a two-stage game with two products sold either under separate brands or under an umbrella brand in both periods.

This paper's central result is that positive quality correlation can arise endogenously in a perfect Bayesian equilibrium. In particular, for some parameter values there are equilibria in which umbrella 
brands always offer products of uniform quality. In these equilibria, the signaling effects are such that firms of any quality profile could make a short term gain by using an umbrella brand; the expected long term impact of the branding decision, however, depends on actual qualities. For firms with one good and one bad product, umbrella branding means putting the future reputation of the good product at stake by inviting consumers to pool their experiences. If future profits are important, these firms will therefore prefer separate branding. For firms with two bad products, on the other hand, the branding decision's expected long term impact can be negligible: if the consumption of a bad product is sufficiently likely to convince consumers of this product's low quality, then bad products can be expected to lose their reputations in the long term irrespectively of the branding decision. Umbrella branding will then be attractive for firms with only bad products, since it allows them to reap short term profit gains without incurring any significant long term losses. Finally, for firms with two good products, umbrella branding is attractive not only in the short but also in the long term: thanks to positive feedback effects, these firms expect to consolidate their products' reputations faster under umbrella than under separate branding.

In contrast, there are no counterintuitive equilibria in which successes (failures) have negative (positive) feedback effects. If consumers expected the qualities of umbrella branded products to be negatively correlated, then firms with two bad products would benefit from positive feedback effects with a higher likelihood than firms with one or two good products. Moreover, the outside option of separate branding is always less profitable for firms with two bad products than for any other firm. These arguments imply that umbrella branding would be particularly attractive for firms with only bad products. Anticipating this, however, consumers' willingness to pay for umbrella branded products would be low. This in turn would render umbrella branding unprofitable for all firms.

The analysis yields several testable implications regarding the circumstances under which umbrella branding is likely to be profitable (absent direct cost considerations) and induce positively correlated beliefs. ${ }^{3}$ First, the prior reputation of the seller's existing product must be high enough. This implies that one would only expect the brands of sufficiently popular products to be successfully extended. Second, the markets for the two products need to be sufficiently symmetric in terms of size. An extension from a mass product to a niche product (or vice versa) cannot be an informative signal about qualities. Third, the seller must attach sufficient weight to both short term and long term profits from both products. Fourth, consumers must be sufficiently uncertain about the qual-

\footnotetext{
${ }^{3}$ As is standard in signaling games, babbling equilibria in which umbrella branding happens but is meaningless exist for all parameter values.
} 
ities of both products at the time of the brand extension. If consumers are already certain about the quality of the firm's existing product, umbrella branding cannot affect beliefs because the old product's reputation can no longer be put at stake.

The second main result of the paper is that umbrella branding affects sellers' incentives to invest in the quality of new products. Consider a model extension in which producers of new goods choose their products' qualities prior to selling. Choosing high quality is associated with a fixed investment cost, privately drawn by each producer from a commonly known probability distribution. In this framework, equilibria in which umbrella branding signals perfect quality correlation continue to exist for suitable parameter values and all share the following feature. Investing in the new product's quality is more attractive for firms with a good existing product, available for an umbrella brand, than for mono-product firms: selling a good new product is more profitable if you can umbrella brand it with a good existing product and thereby benefit (in expectation) from positive feedback effects in both directions. Firms that already sell a product of low quality have the lowest investment incentive. The option to use an umbrella brand hence strengthens the quality investment incentives of firms that already sell a high quality product, but weakens the quality investment incentives of firms that currently sell a low quality product.

The paper is organized as follows. Section 2 discusses the related literature. Section 3 describes the framework. Section 4 presents the main effects of umbrella branding on beliefs and profits; in particular, it explains the relationship between the branding strategy, the correlation of consumers' prior quality perceptions, and signaling and feedback effects. Section 5 contains my main results about the (in)existence of different types of equilibria. Section 6 extends the basic model in two directions. First, by endogenizing the quality of new products, and second, by introducing the possibility that the firm cannot observe the quality of its new product. Section 8 contains concluding remarks. All proofs are in the appendix.

\section{Related Literature}

There are two main extant theories of umbrella branding that allow for endogenous quality correlation while treating product quality as exogenous. Wernerfelt (1988) uses an adverse selection approach where umbrella branding has a signaling function, whereas Choi (1998) analyzes an infinitely repeated game in which sellers choose brands for new products in every period. Both theories focus on showing the existence of an equilibrium in which umbrella brands sell only high quality products that never 
fail. To sustain such an equilibrium, Wernerfelt's (1988) theory relies on pessimistic off-equilibrium beliefs following the failure of an umbrella branded product, while Choi's (1998) model uses the threat of a severe (off-equilibrium) punishment should an umbrella branded product fail. ${ }^{4}$

A weakness of these theories is that, since umbrella branding is a guarantee of high quality and good performance, there cannot be any feedback effects between umbrella branded products on the equilibrium path. This is inconsistent with the empirical evidence that documents successes but also failures of umbrella branded products and their feedback effects (see for example Sullivan 1990; John, Locken and Joiner 1998; Swaminathan, Fox, and Reddy 2001). The model I propose aims to overcome this discrepancy between theoretical predictions and empirical evidence by allowing consumers to continue learning about quality after the branding decision. Whenever buyers believe that the qualities of two umbrella branded products are positively correlated, the success (failure) of one product then has a positive (negative) feedback effect on buyers' perception of the other product's quality on the equilibrium path.

Cabral (2000) proposes an alternative theory of umbrella branding that features ongoing learning and feedback effects (from new on old products, but not vice versa). ${ }^{5}$ Building on the premise that the qualities of umbrella branded products are identical for exogenous reasons, he shows that higher quality sellers have stronger incentives to extend their brands. My paper is complementary to Cabral (2000). As discussed in the introduction, there are situations in which Cabral's assumption of perfect exogenous quality correlation makes limited sense. The theory in this paper shows that the assumption is not needed for consumers to hold correlated beliefs. Moreover, it shows that even with endogenous quality correlation umbrella branding remains a signal of high quality as predicted by Cabral (2000): positive quality correlation can only arise in equilibrium if the umbrella branding decision has signaling effects that imply higher profits in the short term. Finally, my analysis leads to new empirical predictions, and lends itself to extensions that would not be feasible with exogenous quality correlation. First, the endogenous choice of the new product's quality. Second, a possible lack of knowledge about the new product's quality on the side of the seller, capturing a bad 'fit' between the old and the new product.

Endogenous quality choice is the main topic of Andersson (2002), Hakenes and Peitz (2008),

\footnotetext{
${ }^{4}$ Another adverse selection model in which umbrella branding guarantees high quality is Hakenes and Peitz (2009), which compares umbrella branding with external quality certification. Moorthy (2010) discusses the robustness of Wernerfelt's (1988) results and proposes alternative off-equilibrium beliefs.

${ }^{5}$ In my model, there are feedback effects in both directions. This is necessary to derive endogenous quality correlation.
} 
Cabral (2009), and Rasmusen (2010). The key insight of that literature is that umbrella branding can expand the scope for quality provision when firms simultaneously choose both products' qualities. ${ }^{6}$ My analysis of quality provision is different: the existing product's quality is given by past decisions, and the prediction is that umbrella branding strengthens the incentives to invest in the quality of the new product only if the exiting product is already of high quality. To the best of my knowledge, this is the first paper in the branding literature to identify a link between firms' incentives to invest in the qualities of new products and the qualities of their existing products.

Other functions of umbrella branding in the literature are the reduction of uncertainty, either about horizontal product characteristics (Sappington and Wernerfelt 1985) or about quality (Montgomery and Wernerfelt 1992), and the exploitation of the intrinsic value (status or otherwise) of a brand (Pepall and Richards 2002). Rotemberg (2010) analyzes umbrella branding when firms are concerned with being perceived as altruistic towards customers.

\section{Framework}

I consider a two-period model. At the beginning of period $t=1$, a fixed measure of firms, each endowed with one "new" product, is born. In addition, there is a fixed measure of incumbent firms in the economy, each selling one "old" product. One of these incumbents also gets endowed with a new product at the beginning of period $t=1 .^{7}$ The focus of the analysis will be the branding decision of this multi-product firm. ${ }^{8}$ Following the branding decision, all products are sold in periods $t=1$ and $t=2$.

All products are experience goods, each of either good or bad quality. Only firms observe the qualities of their products. Quality determines the relative probabilities of the two possible performance outcomes, success $(S)$ and failure $(F)$. A good product generates a success, i.e. works well,

\footnotetext{
${ }^{6}$ In Andersson (2002), Cabral (2009), and Rasmusen (2010), the basic mechanism ressembles that in Bernheim and Whinston (1990)'s analysis of collusion under multimarket contact. Hakenes and Peitz (2008), using the assumption that high quality products never fail, rely on pessimistic out-of-equilibrium beliefs following the failure of one or both umbrella branded products.

${ }^{7}$ The analysis would be unchanged if instead of just one incumbent, a countable (i.e., measure zero) set of incumbents were endowed with a second product. The results would also continue to hold if each incumbent firm were endowed with a new product with a strictly positive but sufficiently small probability.

${ }^{8}$ The analysis would be the same if instead of being endowed with a second product, an incumbent got randomly matched with an entrant to negotiate a brand licensing agreement (assuming the firms can observe each other's qualities).
} 
with probability $g \in(0,1)$, while a bad product is successful with a lower probability $b \in(0, g)$. Conditional on quality, performances are distributed i.i.d. across periods. In each period, all consumers observe the same product performance, i.e., performance is batch or product generation specific. Consumers' prior belief about the quality of new products is $\gamma \in(0,1)$. At the beginning of period $t=1$, consumers hence assign probability $\gamma$ to any new product being good.

The old product of the multi-product firm, henceforth also simply referred to as "the firm", has reputation $r \in(0,1)$ at the beginning of period $t=1 .^{9}$ The firm's strategy consists of whether or not to extend its existing brand to its new product, given the qualities $q_{o} \in\{b, g\}$ and $q_{n} \in\{b, g\}$ of its old and its new product, respectively. Formally, $x_{q_{o} q_{n}} \in[0,1]$ will denote the probability that the firm chooses an umbrella brand if the product qualities are $q_{o}$ and $q_{n}$. The firm's umbrella branding strategy is hence a vector $\left(x_{g g}, x_{g b}, x_{b g}, x_{b b}\right)$ that gives the probability of a brand extension for every possible quality profile $\left(q_{o}, q_{n}\right)$. For expositional simplicity, this paper will focus on pure strategies, i.e., $x_{q_{o} q_{n}} \in\{0,1\}$ for all $\left(q_{o}, q_{n}\right)$, unless explicitly mentioned otherwise.

Following Tadelis (1999) and Cabral (2000), I assume that consumers do not observe the ownership of each brand. This means that consumers connect two products to the same firm if and only if the firm uses an umbrella brand. If the firm decides to introduce its new product under a separate brand, consumers are unaware that the firm decided against an umbrella brand. This assumption is appropriate for fast moving consumer goods, where firms that have several brands often try to "hide" from consumers that these brands belong to the same firm and consumers are unlikely to expend effort to track products back to their producers. In my framework, this assumption implies that the absence of an umbrella brand does not lead consumers to revise their initial beliefs $\gamma$ and $r$.

Consumers' information set prior to consumption in period 1 thus includes the observation that a firm uses an umbrella brand if that is the case and nothing otherwise. Prior to period 2 consumption decisions, consumers update their beliefs based on the product performances in period 1. The period 1 performances of the two products sold by the multi-product incumbent whose strategy I consider will be denoted by $\sigma_{o} \in\{F, S\}$ and $\sigma_{n} \in\{F, S\}$. Table 1 summarizes the timing.

All consumers have unit demands for all products, and the consumption of a well functioning product procures a utility of one while consumption of a failing product procures zero utility. A

\footnotetext{
${ }^{9}$ The reputations of other old products at the beginning of period $t=1$ can be different from $r$. Since past performances determine the beliefs about old products, it would be inapproriate to impose that consumers hold the same beliefs about all old products.
} 


\section{TABLE 1 Timing}

$t=1$ The firm is endowed with a new product of quality $q_{n}$ and extends its brand with probability $x_{q_{o} q_{n}}$.

Consumers observe brand names and buy one unit of each product.

Consumers observe performances $\sigma_{o}$ and $\sigma_{n}$.

$t=2 \quad$ Consumers buy one unit of each product.

consumer's willingness to pay for a product with reputation $\mu$ is thus

$$
w(\mu) \equiv \mu g+(1-\mu) b
$$

In every period, the firms make take-it-or-leave-it offers to consumers and therefore optimally set each product's price equal to consumers' willingness to pay for that product. ${ }^{10}$ Production costs are zero.

Firms attach weight $\delta \in(0,1)$ to second period profits. Moreover, the markets for the different products that the multi-product firm sells can be asymmetric. The share of the market for the new product in the firm's total sales is denoted by $\beta \in(0,1)$. Normalizing the total number of units that the multi-product firms sells in the two periods to one, consumers then buy $(1-\delta)(1-\beta)$ units of its old product in period $1,(1-\delta) \beta$ units of its new product in period $1, \delta(1-\beta)$ units of its old product in period 2 , and $\delta \beta$ units of its new product in period 2 .

The analysis will focus on equilibria in which the firm uses umbrella branding with positive probability, i.e., $x_{q_{o}, q_{n}}>0$ for some $\left(q_{o}, q_{n}\right) .{ }^{11}$ Since $g, b \in(0,1)$, such equilibria do not contain any off-equilibrium beliefs. A (Bayesian) equilibrium consists of a belief system and an umbrella branding strategy $\left(x_{g g}, x_{g b}, x_{b g}, x_{b b}\right)$ such that (i) the branding strategy maximizes the firm's expected profits given beliefs, and (ii) beliefs are Bayesian consistent given the branding strategy.

\footnotetext{
${ }^{10}$ This way of modeling demand and prices is common in the theoretical literature on brands (see Tadelis 1999; Cabral 2000, 2009; Hakenes and Peitz 2007, 2008, 2009). It allows me to set aside prices as quality signals, an issue dealt with extensively elsewhere in the literature (Wolinsky 1983; Milgrom and Roberts 1986; Bagwell and Riordan 1991).

${ }^{11}$ Pooling equilibria in which $x_{q_{o}, q_{n}}=0$ for all $\left(q_{o}, q_{n}\right)$ obviously always exist if the off-equilibrium beliefs following a deviation to umbrella branding are sufficiently pessimistic. A more interesting question is to establish conditions for the existence of equilibria in which umbrella branding happens.
} 


\section{Signaling and Feedback Effects}

\subsection{The Impact of Umbrella Branding on Beliefs}

Umbrella branding can induce two types of effects on beliefs. First, the decision to umbrella brand on its own may be a quality signal. For the new product, for example, such a signaling effect occurs whenever consumers believe that a new product introduced under an umbrella brand is either more or less likely to be of high quality than new products carrying unknown brand names. These signaling effects are relevant both for first and second period beliefs.

Second, umbrella branding leads feedback effects whenever consumers believe that the qualities of umbrella branded products are correlated. The success or failure of one product, say the new product, then induces consumers to revise their beliefs not only about the new product itself but also about the old product. Since these feedback effects are linked to performance observations that first occur at the end of period one, feedback effects are only relevant for the analysis of second period beliefs.

Period 1 To analyze the short term signaling effects of umbrella branding, I compare consumers' beliefs at the beginning of the first period under umbrella branding and under separate branding. As explained in the previous section, consumers do not revise their priors $r$ and $\gamma$ about the qualities of the multi-product firm's products if the firm uses separate brands. Confronted with an umbrella brand, however, consumers possibly revise their beliefs about both products' qualities. Whenever brand extensions happen with positive probability in equilibrium, all beliefs can be obtained by Bayesian updating. I denote by $\mu_{q_{o} q_{n}}$ the probability consumers assign to the quality profile $\left(q_{o}, q_{n}\right)$ if they observe an umbrella brand; for example: ${ }^{12}$

$$
\mu_{g g}=\frac{r \gamma x_{g g}}{r \gamma x_{g g}+r(1-\gamma) x_{g b}+(1-r) \gamma x_{b g}+(1-r)(1-\gamma) x_{b b}} .
$$

${ }^{12}$ The probabilities consumers assign to the quality profiles other than $(g, g)$ are

$$
\begin{aligned}
\mu_{g b} & =\frac{r(1-\gamma) x_{g b}}{r \gamma x_{g g}+r(1-\gamma) x_{g b}+(1-r) \gamma x_{b g}+(1-r)(1-\gamma) x_{b b}}, \\
\mu_{b g} & =\frac{(1-r) \gamma x_{b g}}{r \gamma x_{g g}+r(1-\gamma) x_{g b}+(1-r) \gamma x_{b g}+(1-r)(1-\gamma) x_{b b}}, \text { and } \\
\mu_{b b} & =\frac{(1-r)(1-\gamma) x_{b b}}{r \gamma x_{g g}+r(1-\gamma) x_{g b}+(1-r) \gamma x_{b g}+(1-r)(1-\gamma) x_{b b}} .
\end{aligned}
$$


To simplify notations, let me denote the aggregate belief that the old product of the umbrella brand is good by

$$
\mu^{o}=\mu_{g g}+\mu_{g b}
$$

and the belief that the new product is good by

$$
\mu^{n}=\mu_{g g}+\mu_{b g}
$$

Umbrella branding has a positive signaling effect on the new product if and only if it improves the consumers' belief about the quality of the new product, i.e., whenever

$$
\mu^{n}>\gamma
$$

This condition is satisfied whenever, given the prior $r$ about the quality of the old product, a brand extension is more likely to involve a good rather than a bad new product:

$$
r x_{g g}+(1-r) x_{b g}>r x_{g b}+(1-r) x_{b b}
$$

Similarly, the signaling effect on the core product is positive if and only if

$$
\mu^{o}>r
$$

Period 2 After period 1 consumption, consumers observe the performances of both products. They then update their beliefs so as to take into account these additional pieces of information in the second period.

Under separate branding, the updating of beliefs is "standard" in the sense that consumers only take into account each product's own performance. If the old product succeeds in the first period, for example, consumers update their belief that the old product is of high quality from $r$ to

$$
\lambda_{S}(r) \equiv \frac{r g}{r g+(1-r) b} .
$$

Similarly, if the new product fails, consumers revise their belief that it is of high quality from $\gamma$ to

$$
\lambda_{F}(\gamma) \equiv \frac{\gamma(1-g)}{\gamma(1-g)+(1-\gamma)(1-b)}
$$

The updated belief after a failure of the old product is then $\lambda_{F}(r)$, and the updated belief following a success of the new product is $\lambda_{S}(\gamma)$.

Under umbrella branding, consumers update their period 1 beliefs $\mu^{o}$ and $\mu^{n}$ not only taking into account each product's own performance, but possibly also the brand's overall performance. Consider 
consumers' belief about the old product after a success of this product for example. If consumers ignored the new product's performance, then their second period belief would simply be $\lambda_{S}\left(\mu^{o}\right)$. Now suppose that the new product was successful, too, and that consumers use this additional information. In that case, the belief consumers hold about the old product "before" taking account of the old product's own performance, is no longer $\mu^{o}$ but instead

$$
\mu_{S}^{o}=\frac{\mu_{g g} g+\mu_{g b} b}{\left(\mu_{g g}+\mu_{b g}\right) g+\left(\mu_{g b}+\mu_{b b}\right) b} .
$$

The "final" belief consumers assign to the core product being good if both products were successful in the first period is then simply

$$
\lambda_{S}\left(\mu_{S}^{o}\right)=\frac{\mu_{g g} g^{2}+\mu_{g b} g b}{\mu_{g g} g^{2}+\mu_{g b} g b+\mu_{b g} b g+\mu_{b b} b^{2}} .
$$

The success of the new product has a positive feedback effect on the old product if and only if

$$
\mu_{S}^{o}>\mu^{o}
$$

The beliefs consumers hold about the quality of the new product, or after observing different performance outcomes, can be obtained using the same hypothetical two-step procedure. First, the observation of product $-i$ 's performance $\sigma_{-i}$ has a feedback effect on the belief about product $i$ 's quality $(i \neq-i)$, captured by the revision from $\mu^{i}$ to $\mu_{\sigma_{-i}}^{i}{ }^{13}$ Second, consumers update their belief to take into account product $i$ 's own performance $\sigma_{i}$, which amounts to a revision from $\mu_{\sigma_{-i}}^{i}$ to $\lambda_{\sigma_{i}}\left(\mu_{\sigma_{-i}}^{i}\right)$. The following table summarizes second period beliefs as a function of the pieces of information (umbrella versus separate branding, and the products' performances) consumers have:

\begin{tabular}{|l|l|l|l|l|}
\hline & $S$ of old, $S$ of new & $S$ of old, $F$ of new & $F$ of old, $S$ of new & $F$ of old, $F$ of new \\
\hline umbrella brand & $\lambda_{S}\left(\mu_{S}^{o}\right), \lambda_{S}\left(\mu_{S}^{n}\right)$ & $\lambda_{S}\left(\mu_{F}^{o}\right), \lambda_{F}\left(\mu_{S}^{n}\right)$ & $\lambda_{F}\left(\mu_{S}^{o}\right), \lambda_{S}\left(\mu_{F}^{n}\right)$ & $\lambda_{F}\left(\mu_{F}^{o}\right), \lambda_{F}\left(\mu_{F}^{n}\right)$ \\
\hline separate brands & $\lambda_{S}(r), \lambda_{S}(\gamma)$ & $\lambda_{S}(r), \lambda_{F}(\gamma)$ & $\lambda_{F}(r), \lambda_{S}(\gamma)$ & $\lambda_{F}(r), \lambda_{F}(\gamma)$ \\
\hline
\end{tabular}

${ }^{13}$ In the cases ignored so far, the beliefs after the first step of the revision are

$$
\begin{aligned}
\mu_{F}^{o} & =\frac{\mu_{g g}(1-g)+\mu_{g b}(1-b)}{\left(\mu_{g g}+\mu_{b g}\right)(1-g)+\left(\mu_{g b}+\mu_{b b}\right)(1-b)}, \\
\mu_{S}^{n} & =\frac{\mu_{g g} g+\mu_{b g} b}{\left(\mu_{g g}+\mu_{g b}\right) g+\left(\mu_{b g}+\mu_{b b}\right) b}, \text { and } \\
\mu_{F}^{n} & =\frac{\mu_{g g}(1-g)+\mu_{b g}(1-b)}{\left(\mu_{g g}+\mu_{g b}\right)(1-g)+\left(\mu_{b g}+\mu_{b b}\right)(1-b)} .
\end{aligned}
$$


After any realization of performances, the effect of umbrella branding on the second period belief about each product can then be decomposed into two effects. Following two successes, for example, the impact of umbrella branding on the old product's reputation is

$$
\lambda_{S}\left(\mu_{S}^{o}\right)-\lambda_{S}(r)=\left[\lambda_{S}\left(\mu_{S}^{o}\right)-\lambda_{S}\left(\mu^{o}\right)\right]+\left[\lambda_{S}\left(\mu^{o}\right)-\lambda_{S}(r)\right]
$$

The first term between brackets is positive if and only if the success of the new product has a positive feedback effect on the old product. The second term is positive if and only if umbrella branding has a positive signaling effect on the old product.

Quality Correlation and Feedback Effects Calculating the correlation coefficient between the (prior) quality perceptions of umbrella branded products yields

$$
\rho=\frac{\mu_{g g} \mu_{b b}-\mu_{g b} \mu_{b g}}{\sqrt{\left(\mu_{g g}+\mu_{g b}\right)-\left(\mu_{g g}+\mu_{g b}\right)^{2}} \sqrt{\left(\mu_{g g}+\mu_{b g}\right)-\left(\mu_{g g}+\mu_{b g}\right)^{2}}} .
$$

This correlation is positive if and only if

$$
\mu_{g g} \mu_{b b}>\mu_{g b} \mu_{b g}
$$

Relying on this simply condition, it is straightforward to check that for any $i \in\{o, n\}$,

$$
\begin{aligned}
& \mu_{S}^{i}>\mu^{i}>\mu_{F}^{i} \quad \text { if and only if } \quad \rho>0, \\
& \mu_{S}^{i}=\mu^{i}=\mu_{F}^{i} \quad \text { if and only if } \quad \rho=0, \\
& \mu_{S}^{i}<\mu^{i}<\mu_{F}^{i} \quad \text { if and only if } \quad \rho<0 .
\end{aligned}
$$

If consumers believe that the qualities of umbrella branded products are positively correlated $(\rho>0)$, then successes have positive feedback effects. Conversely, if $\rho<0$, then the success of any one of the products has a negative feedback effect on the other product's reputation. For $\rho=0$, there are no feedback effects at all.

\subsection{The Impact of Umbrella Branding on Profits}

Given beliefs, one can analyze the firm's incentive to use an umbrella brand by considering the marginal impact of umbrella branding on expected aggregate profits. I denote by $\Delta_{1}$ the difference between the first period profits under umbrella branding and under separate branding:

$$
\Delta_{1}=(1-\beta)\left[w\left(\mu^{o}\right)-w(r)\right]+\beta\left[w\left(\mu^{n}\right)-w(\gamma)\right]
$$


Similarly, $\Delta_{2}\left(\sigma_{o}, \sigma_{n}\right)$ denotes the (ex post) difference in second period profits between umbrella and separate branding, following the performance profile $\left(\sigma_{o}, \sigma_{n}\right)$ :

$$
\Delta_{2}\left(\sigma_{o}, \sigma_{n}\right)=(1-\beta)\left[w\left(\lambda_{\sigma_{o}}\left(\mu_{\sigma_{n}}^{o}\right)\right)-w\left(\lambda_{\sigma_{o}}(r)\right)\right]+\beta\left[w\left(\lambda_{\sigma_{n}}\left(\mu_{\sigma_{o}}^{n}\right)\right)-w\left(\lambda_{\sigma_{n}}(\gamma)\right)\right] .
$$

For example,

$$
\Delta_{2}(S, F)=(1-\beta)\left[w\left(\lambda_{S}\left(\mu_{F}^{o}\right)\right)-w\left(\lambda_{S}(r)\right)\right]+\beta\left[w\left(\lambda_{F}\left(\mu_{S}^{n}\right)\right)-w\left(\lambda_{F}(\gamma)\right)\right] .
$$

Finally, $\Delta\left(q_{o}, q_{n}\right)$ denotes the total difference in expected profits between umbrella and separate branding, which is equal to the weighted sum of the first period and expected second period profit differences:

$$
\Delta\left(q_{o}, q_{n}\right)=(1-\delta) \Delta_{1}+\delta E\left[\Delta_{2}\left(\sigma_{o}, \sigma_{n}\right) \mid q_{o}, q_{n}\right]
$$

where

$$
\begin{aligned}
E\left[\Delta_{2}\left(\sigma_{o}, \sigma_{n}\right) \mid\right. & \left.q_{o}, q_{n}\right]=q_{o} q_{n} \Delta_{2}(S, S)+q_{o}\left(1-q_{n}\right) \Delta_{2}(S, F) \\
& +\left(1-q_{o}\right) q_{n} \Delta_{2}(F, S)+\left(1-q_{o}\right)\left(1-q_{n}\right) \Delta_{2}(F, F) .
\end{aligned}
$$

The branding strategy $\left(x_{g g}, x_{g b}, x_{b g}, x_{b b}\right)$ is optimal if and only if for all $\left(q_{o}, q_{n}\right)$ :

$$
x_{q_{o} q_{n}}=\left\{\begin{array}{cl}
1 & \text { if } \Delta\left(q_{o}, q_{n}\right)>0, \\
\text { any } \varepsilon \in[0,1] & \text { if } \Delta\left(q_{o}, q_{n}\right)=0, \\
0 & \text { if } \Delta\left(q_{o}, q_{n}\right)<0 .
\end{array}\right.
$$

The Umbrella Branding Strategy and Quality Correlation The next step is to link the branding strategy to the correlation of consumers' quality perceptions. It is easy to check that

$$
\rho>0 \text { if and only if } x_{g g} x_{b b}>x_{g b} x_{b g} .
$$

Perfect positive correlation $(\rho=1)$ obtains for any branding strategy such that $x_{g b}=x_{b g}=0$ but $x_{g g}, x_{b b}>0$. Perfect negative correlation $(\rho=-1)$ obtains for any branding strategy such that umbrella branding always involves products of opposite qualities, i.e., if $x_{g g}=x_{b b}=0$ but $x_{g b}, x_{b g}>0$.

The Profit Impact of Signaling and Feedback Effects To illustrate the impact of the signaling and feedback effects on profits, note first that in

$$
\begin{gathered}
\Delta_{1}=(1-\beta) \underbrace{\left[w\left(\mu^{o}\right)-w(r)\right]}_{\text {short run price impact of the signaling effect on the old product }} \\
+\beta \underbrace{\left[w\left(\mu^{n}\right)-w(\gamma)\right]}_{\text {short run price impact of the signaling effect on the new product }},
\end{gathered}
$$


the first term is positive if and only if the signaling effect on the core product is positive, and the second term is positive if and only if the signaling effect on the extension product is positive.

The expected second period profit difference can be decomposed as follows:

$$
\begin{aligned}
& E\left[\Delta_{2}\left(\sigma_{o}, \sigma_{n}\right) \quad \mid \quad q_{o}, q_{n}\right]= \\
& (1-\beta) \quad \underbrace{E\left[w\left(\lambda_{\sigma_{o}}\left(\mu_{\sigma_{n}}^{o}\right)\right)-w\left(\lambda_{\sigma_{o}}\left(\mu^{o}\right)\right) \mid q_{o}, q_{n}\right]} \\
& \text { expected price impact of the feedback effect on the old product } \\
& +(1-\beta) \quad \underbrace{E\left[w\left(\lambda_{\sigma_{o}}\left(\mu^{o}\right)\right)-w\left(\lambda_{\sigma_{o}}(r)\right) \mid q_{o}\right]} \\
& \text { expected long term price impact of the signaling effect on the old product } \\
& +\beta \quad \underbrace{E\left[w\left(\lambda_{\sigma_{n}}\left(\mu_{\sigma_{o}}^{n}\right)\right)-w\left(\lambda_{\sigma_{n}}\left(\mu^{n}\right)\right) \mid q_{o}, q_{n}\right]} \\
& \text { expected price impact of the feedback effect on the new product } \\
& +\beta \quad \underbrace{E\left[w\left(\lambda_{\sigma_{n}}\left(\mu^{n}\right)\right)-w\left(\lambda_{\sigma_{n}}(\gamma)\right) \mid q_{n}\right]}_{\text {expected long term price impact of the signaling effect on the }}
\end{aligned}
$$

Since $\lambda_{S}(\cdot)$ and $\lambda_{F}(\cdot)$ are both increasing, the "expected long term price impact of the signaling effect on the old product" is positive if and only if $\mu^{o}>r$. Similarly, for the new product, the expected long term price impact of the signaling effect is positive if and only if $\mu^{n}>\gamma$. The signs of these effects are hence independent of the concerned products' quality; their magnitudes, however, generally vary with quality.

As already explained in the section on beliefs, given the sign of the correlation coefficient $\rho$, it is easy to assess the signs of the two feedback effects ex post. For $\rho>0$, for example, a success of the extension product has a positive feedback effect on the (price of the) core product. The following lemma shows that knowledge of the quality of product $-i$ is sufficient to also assess the "expected price impact of the feedback effect on product $i "$ :

Lemma 1 - For $\rho>0$, the expected price impact of the feedback effect on product $i \in\{o, n\}$ is positive if and only if product $-i \neq i$ is good. Formally, for any $q_{o} \in\{b, g\}$ :

$$
E\left[w\left(\lambda_{\sigma_{o}}\left(\mu_{\sigma_{n}}^{o}\right)\right)-w\left(\lambda_{\sigma_{o}}\left(\mu^{o}\right)\right) \mid q_{o}, q_{n}\right]>0 \text { if and only if } q_{n}=g
$$

and for any $q_{n} \in\{b, g\}$ :

$$
E\left[w\left(\lambda_{\sigma_{n}}\left(\mu_{\sigma_{o}}^{n}\right)\right)-w\left(\lambda_{\sigma_{n}}\left(\mu^{n}\right)\right) \mid q_{o}, q_{n}\right]>0 \text { if and only if } q_{o}=g
$$

- For $\rho<0$, the expected price impact of the feedback effect on product $i \in\{o, n\}$ is positive if and only if product $-i \neq i$ is bad. 
In some instances, Lemma 1 will prove helpful in evaluating the total impact of umbrella branding on profits: the Lemma implies for example that if (i) $\rho>0$ and (ii) both signaling effects are nonnegative, then $\Delta(g g)>0$.

\section{Equilibria}

\subsection{Positive Quality Correlation}

In this section, I first discusses some general characteristics of equilibria with positive quality correlation $(\rho>0)$ and then provide conditions under which an equilibrium with perfect positive quality correlation exists.

In any equilibrium with positive quality correlation, umbrella branding must be profitable if both products are of the same quality. Hence, the following two conditions must be met:

$$
\Delta(g, g) \geq 0, \text { and } \Delta(b, b) \geq 0 .
$$

Intuitively, the condition $\Delta(g, g) \geq 0$ is easy to satisfy. If $\rho>0$ in equilibrium, then feedback effects have a positive expected long term impact for a firm with two good products (see Lemma 1). Hence, as long as the signaling effects are not too adverse, umbrella branding is profitable for a firm with two good products.

It is more difficult to induce a firm with two bad products to umbrella brand: by Lemma 1, the expected total impact of the feedback effects is negative for such a firm. For the condition $\Delta(b, b) \geq 0$ to hold in spite of this, umbrella branding must have a positive signaling effect on at least one of the products. This implies the following result:

Lemma 2 If $\rho>0$ in equilibrium, then umbrella branding has a positive signaling effect on the old and/or the new product.

This implication is consistent with the empirical evidence, which suggests that extending a brand can bring benefits for existing products (Sullivan 1990; Balachander and Ghose 2003), and that on average products introduced as brand extensions meet more initial success than products carrying unknown brand names (Claycamp and Liddy 1969; Smith and Park 1992). ${ }^{14}$

\footnotetext{
${ }^{14}$ Smith and Park (1992) also find that "the brand extension-new brand differential in the revenue component of cash flow widens as brand strength increases". Interpreting brand strength as the initial reputation $r$ of the core product, this finding is consistent with positive quality correlation: as can be easily checked, the signaling effect on the new product, $\mu^{n}-\gamma$, increases in $r$ in any equilibrium with $\rho>0$.
} 
For positive quality correlation to arise, it is also necessary that

$$
\Delta(g, b) \leq 0, \text { or } / \text { and } \Delta(b, g) \leq 0
$$

Intuitively, it seems difficult to reconcile any one of these conditions with $\Delta(b, b) \geq 0$ : failures have negative feedback effects here, and failures are most likely when both products are bad. To explain why a firm with products of differing qualities may nevertheless have lower incentives to use umbrella brands than a firm with two bad products, one needs to consider the sizes of these expected negative feedback effects. To fix ideas, let me focus on candidate equilibria in which $x_{g b}<1$, which requires that $\Delta(g, b) \leq 0$. In any such equilibrium, it must be that

$$
\Delta(b, b) \geq \Delta(g, b)
$$

This condition is equivalent to

$$
E\left[\Delta_{2}\left(\sigma_{o}, \sigma_{n}\right) \mid b, b\right] \geq E\left[\Delta_{2}\left(\sigma_{o}, \sigma_{n}\right) \mid g, b\right],
$$

or

$$
\begin{aligned}
& b E\left[\Delta_{2}\left(S, \sigma_{n}\right) \mid q_{n}=b\right]+(1-b) E\left[\Delta_{2}\left(F, \sigma_{n}\right) \mid q_{n}=b\right] \\
\geq & g E\left[\Delta_{2}\left(S, \sigma_{n}\right) \mid q_{n}=b\right]+(1-g) E\left[\Delta_{2}\left(F, \sigma_{n}\right) \mid q_{n}=b\right] .
\end{aligned}
$$

Clearly, the latter condition holds if and only if

$$
E\left[\Delta_{2}\left(F, \sigma_{n}\right) \mid q_{n}=b\right] \geq E\left[\Delta_{2}\left(S, \sigma_{n}\right) \mid q_{n}=b\right]
$$

Hence, given the new product is bad, umbrella branding must be less attractive relative to separate branding if the old product succeeds than if it fails. How is this possible, given that a success of the old product has a positive feedback effect on the new product under umbrella branding? ${ }^{15}$ If $q_{n}=b$, then the new product is likely to fail, which induces a negative feedback effect under umbrella branding. The key point is that this negative feedback effect from the new on the old product can be stronger if the old product succeeds than if it fails. If the old product's failure already gives consumers a strong indication of bad quality, then the new product's failure merely provides some additional evidence pointing into the same direction. If the old product succeeds, however, then the

\footnotetext{
${ }^{15}$ Any success (failure) also has a positive (negative) direct effect on the product concerned itself. The branding decision can have an impact on the size, but not the sign, of this effect. My discussion in the main text focuses on feedback effects instead, since these are key to understanding endogenous quality correlation.
} 
negative feedback effect can severely damage the old product's reputation. Intuitively, this is the case if consumers expect a strong quality correlation and failures are strong indications of low quality while successes leave open the possibility that the product is bad. Separate branding can then be attractive for a mixed quality firm because it allows the firm to shelter the reputation of the good product.

The following proposition shows that for $g$ sufficiently close to 1 , there indeed always exists a non-empty set of values of the other parameters such that in equilibrium umbrella branding signals that products are of identical qualities:

Proposition 1 There exist thresholds $\underline{r}(\gamma, \beta) \in(0,1), \bar{b}(r, \gamma, \beta) \in(0,1), \underline{\delta}(r, \gamma, \beta, b) \in(0,1)$ and $\bar{\delta}(r, \gamma, \beta, b) \in(\underline{\delta}(\cdot), 1)$ such that for $g$ sufficiently close to 1 , a (pure strategy) equilibrium with $\rho=1$ exists if

i) $r$ is high enough so that, given the branding strategy $(1,0,0,1)$, the decision to umbrella brand increases short term profits:

$$
\Delta_{1}>0 \leftrightarrow r>\underline{r}(\gamma, \beta)
$$

ii) quality differences are sufficiently large:

$$
b \in(0, \bar{b}(r, \gamma, \beta)), \text { and }
$$

iii) the firm attaches sufficient weight to both present and future profits:

$$
\underline{\delta}(r, \gamma, \beta, b)<\delta<\bar{\delta}(r, \gamma, \beta, b) .
$$

The condition that $g$ is close to 1 ensures that failures are sufficiently strong indications of low quality. This implies that if the performances of two umbrella branded products differ, the negative feedback effect from the failure dominates the positive feedback effect from the success. In the limit, for $g$ equal to 1 , consumers will always conclude that both products are bad. Therefore, $\Delta_{2}(F, S)$ and $\Delta_{2}(S, F)$ are negative for large enough $g$. Moreover, two failures almost fully convince consumers that both products are bad, under umbrella as well as under separate branding. Hence, $\lim _{g \rightarrow 1} \Delta_{2}(F, F)=0$. Condition ii) in Proposition 1 ensures that bad products fail with a high enough probability. This implies that firms with products of differing qualities are indeed very likely to experience one success and one failure, and will hence lose profits in the long term by opting for an umbrella brand. For firms with two bad products, on the other hand, two failures are sufficiently more likely, so that the long term effect of umbrella branding is small. 
Condition i) guarantees that $\Delta_{1}>0$, which implies that for sufficiently low discount factors umbrella branding is profitable for firms with two bad products. If both products are bad but the initial belief $r$ happens to be high enough due to luck in the past, it is optimal to umbrella brand to maximally exploit the brand's existing reputation in the short run. However, for too low discount factors, $\Delta_{1}>0$ implies that umbrella branding would also be profitable for firms with products of differing qualities; condition iii) is therefore needed to ensure that the discount factor lies in an intermediate range.

Before moving to negative quality correlation, let me make some remarks on the existence of positive quality correlation equilibria different from the one in Proposition 1. First, mixed strategy equilibria such that $\rho=1$ can also exist. The sufficient conditions for such equilibria are qualitatively similar to those in Proposition 1 (except that the condition $\Delta(b, b)=0$ now exactly pins down the discount factor given all other parameters). In such equilibria, $x_{g g}=1$ and $x_{b b} \in(0,1)$. To see why $x_{g g}=1$, note that the proof of Proposition 1 does not rely on the purity of the equilibrium strategy to show that $\Delta_{1}>0$ is a necessary condition for an equilibrium with perfect correlation and that $\Delta_{1}>0$ implies $\lim _{g \rightarrow 1} \Delta(g, g)>0$, which in turn implies $x_{g g}=1$. Second, there can be equilibria in which $\rho \in(0,1)$. In particular, any strategy $\left(1, x_{g b}, x_{b g}, x_{b b}\right)$ such that $\rho>0$ and at most one firm type mixes is an equilibrium under conditions that are qualitatively similar those in Proposition $1 .^{16}$

\subsection{Negative Quality Correlation: An Inexistence Result}

Whenever $\rho<0$, successes (failures) have negative (positive) feedback effects. This is clearly counterintuitive, and the empirical and experimental evidence strongly indicates the opposite. It turns out that (unlike in some existing frameworks) negative quality equilibria cannot exist in my model. This implies that no equilibrium selection criterion needs to be invoked to rule out such counterintuitive situations.

Proposition 2 There does not exist any equilibrium in which $\rho<0$.

To understand the intuition behind this result, consider perfect negative correlation first. In that case, umbrella branding convinces consumers that one product is good and one product is bad, without them knowing which product is the good one. If the firm chooses umbrella branding, the success of product $i \neq-i \in\{o, n\}$ then has a positive direct impact on consumers' belief about $i$ 's

\footnotetext{
${ }^{16}$ Obviously, $x_{g b}$ can be different from $x_{b g}$ in any such equilibrium only if $r \neq \gamma$ and/or $\beta \neq \frac{1}{2}$; otherwise, there are only three distinct firm types.
} 
quality that is exactly equal to its negative feedback effect on consumers' belief about product $-i$. Under separate branding, on the other hand, successes have positive direct effects but no negative feedback effects. This implies that a firm with two bad products has a stronger incentive to umbrella brand than either a firm with a good old and a bad new product and/or a firm with a bad old and good new product. ${ }^{17}$ In other words, umbrella branding is particularly attractive for firms with two bad products, since (i) the outside option of separate branding is less attractive for the $(b, b)$-type than for any other type, and (ii) successes, which are more likely to be experienced by firms with one good product, induce large negative feedback effects under umbrella branding.

Firms with two bad products hence cannot be kept from umbrella branding in any candidate equilibrium with negative quality correlation. For $x_{b b}=1$, however, there does not exist any equilibrium such that $\rho<0$ either. The reason is that signaling effects decrease in $x_{b b}$, and it is impossible to offset this stigmatization of umbrella brands by means of a high $x_{g g}$ without inducing positive quality correlation.

\subsection{Equilibria without Feedback Effects}

There are potentially two kinds of equilibria without feedback effects $(\rho=0)$ : (i) equilibria in which umbrella branding allows consumers to fully infer the quality of one or both products, and (ii) 'babbling' equilibria in which umbrella branding happens but has no impact on beliefs and prices.

A multi-product firm would clearly like consumers to believe that both its products are good. However, even a firm with one or several bad products wants consumers to hold such beliefs, and the certification provided by umbrella branding would actually be more valuable for such a firm than for one with good products: since under separate branding consumers are more likely to revise their beliefs downwards when products are bad rather than good, the outside option of separate branding is less attractive the higher the number of bad products. As a result, there cannot be any equilibrium in which umbrella branding signals that both products are good. By the same reasoning, umbrella branding cannot guarantee the quality of only one of the two products either. The following proposition summarizes this discussion (a formal proof can be found in the appendix):

Proposition 3 There does not exist any equilibrium in which umbrella branding fully reveals the high quality of the old and/or the new product.

\footnotetext{
${ }^{17}$ The relative importance $\beta$ of the different products determines whether $\Delta(b, b)>\Delta(g, b)$ or $\Delta(b, b)>\Delta(b, g)$ or both. For $\beta=\frac{1}{2}$, both inequalities hold.
} 
Note that this result relies on the assumption that good products can fail (possibly with a very small probability), so that consumers who are convinced a product is good do not revise their beliefs downwards even after observing a failure. If $g$ were exactly equal to 1 , then an equilibrium in which umbrella branding guarantees high quality could be sustained by specifying sufficiently pessimistic off-equilibrium beliefs following the failure of an umbrella branded product (see Wernerfelt 1988; Hakenes and Peitz 2008; Moorthy 2010).

Babbling equilibria, on the other hand, always exist. If $x_{q_{o} q_{n}}=1$ for all $\left(q_{o}, q_{n}\right)$, then umbrella branding does not affect beliefs. This in turn implies that the firm is indifferent between umbrella branding and separate branding, so the strategy is indeed optimal. The following proposition provides a number of structural conditions under which only babbling equilibria exist:

Proposition 4 Any equilibrium is a babbling equilibrium if - ceteris paribus - one of the following conditions is satisfied:

i) The markets for the old and for the new product are too asymmetric, i.e., $\beta$ is too close to 0 or to 1 .

ii) The consumers' prior about one of the products is already very accurate, i.e., $r$ is too close to 1 or to 0 , or $\gamma$ is too close to 1 or to 0 .

iii) Firms are too impatient, i.e., $\delta$ is too close to 0.

iv) Quality differences are too small, i.e., $b$ is too close to $\mathrm{g}$.

For umbrella branding to affect beliefs, the firm's branding incentives must depend on its quality profile. This requires that profits are sufficiently responsive to the performances of both products. A prerequisite for this is of course that beliefs are sufficiently responsive to performances. It is easy to see why this cannot be the case in the last two situations treated in the proposition. For $b$ too close to $g$, beliefs hardly respond to performance observations. If $\delta$ is too close to 0 , then intertemporal profits are not at all responsive to performances, as future profits do not receive any weight. These two necessary conditions for a non-babbling equilibrium echo conditions ii) and iii) of Proposition 1.

If consumers are already very well-informed about the quality of one of the products (case ii)), then (i) umbrella branding cannot affect the price of this product in either the short or the long run, ${ }^{18}$

\footnotetext{
${ }^{18}$ John, Loken and Joiner (1998) provide experimental evidence that extreme beliefs and beliefs about flagship products, which can be expected to be more precise than beliefs about other products, are resistant to negative feedback effects from extension products that do not share the core product's quality attributes.
} 
and (ii) beliefs almost do not respond to this product's performance. This means that the signaling effect on the other product will drive the branding decision. Since the sign of that effect is the same for all quality profiles, however, there is no way to induce some firm types to umbrella brand with a higher probability than other firm types, which would be necessary to create a signaling effect in the first place. Smith and Park (1992) provide evidence consistent with result ii) of Proposition 1 in a study based on survey data about a large range of consumer products. They find that the better consumers' knowledge of the new product the weaker are the effects of brand extensions. ${ }^{19}$

Finally, if markets are very asymmetric, branding decisions depend almost exclusively on the profit impact on one single product. Consider a brand extension from a mass category to a niche category for example ( $\beta$ close to 0$)$. Then, the performance of the new product matters mainly because of its feedback effect on the old product. The old product's performance, on the other hand, is important mainly with respect to its impact on the belief about the old product itself. Performances thus have two instead of four relevant effects on profits, which, as shown in the proof of Proposition 4, does not suffice to sustain a non-babbling equilibrium.

Since no negative quality correlation equilibria exist, Proposition 4 implies that the following conditions are necessary for a positive quality correlation equilibrium: (i) the firm puts sufficient weight on the profits from selling both the old and the new product, (ii) the firm puts sufficient weight on future profits, (iii) consumers are relatively ill-informed about both products' qualities at the moment of the brand extension, and (iv) good products are sufficiently superior to bad products.

\section{Extensions}

\subsection{Investments in Product Quality}

This section considers a model extension that endogenizes the qualities of new products. The key difference with respect to the baseline model is that prior to product launch any firm endowed with a new product, i.e., the multi-product firm and every entrant, must decide whether to make a onetime investment to ensure that $q_{n}=g$; absent the investment, $q_{n}=b$. For each firm, the cost $c$ of the quality-improving investment is a random draw from the uniform distribution with support

\footnotetext{
${ }^{19}$ Note that condition ii) of Proposition 4 does not contradict condition i) of Proposition 1 . For any $r$ that satisfies condition i) of Proposition 1, there exists a set of the other parameter values such that perfect positive quality correlation is an equilibrium. Keeping all other parameters fixed, however, a perfect quality correlation equilibrium can only exist if $r$ is not too close to 1 .
} 
$[0, \beta(g-b)]$, where the upper bound is chosen so as to equal the profit (and welfare) gain from the investment under symmetric information.

All firms with new products observe their realization of $c$ prior to the investment decision stage. The multi-product incumbent makes the investment and branding decisions simultaneously. ${ }^{20}$ Consumers cannot observe investment decision and product qualities, but are aware of the probability distribution of the investment cost. A strategy for an entrant consists of an investment decision rule as a function of the realization of $c$. A strategy for the multi-product incumbent firm consists of a rule determining both the investment and the umbrella branding decision as a function of $c$ and $q_{o}$. In equilibrium, each firm chooses a strategy that maximizes its expected profits given beliefs, and beliefs are Bayesian consistent with the firms' strategies. ${ }^{21}$

My goal is to find out whether and how the investment incentives of a multi-product incumbent depend on $q_{o}$, and how they compare to the incentives of an entrant. Since the investment cost is random, any set of strategies induces three investment probabilities: one for entrants, one for the multi-product firm if $q_{o}=g$, and one the multi-product firm if $q_{o}=b$. These probabilities will be denoted by $i, i_{g}$, and $i_{b}$, respectively. As before, perfect positive quality correlation means that $\mu_{g g}, \mu_{b b}>0$ while $\mu_{g b}=\mu_{b g}=0$, where these beliefs now depend on the anticipated joint investment/branding decision of the multi-product firm.

Proposition 5 Suppose an equilibrium in which umbrella branding signals perfect quality correlation exists. Then,

$$
i_{b} \leq i \leq i_{g}
$$

and $0<i<1$ in this equilibrium.

Proposition 5 shows that in any equilibrium with perfect positive quality correlation having the option to use an umbrella brand affects the optimal investment decision. In particular, the umbrella branding option introduces a tendency to align the new product's quality to that of the existing product. In fact, the inequalities in Proposition 5 are strict whenever the multi-product firm has a strict preference for umbrella branding when both products are good and a strict preference for separate branding when both products are bad.

The intuition is straightforward. Given perfect quality correlation, a firm with the option to umbrella brand faces the choice between (i) selecting quality $q_{n}=q_{o}$ and umbrella branding, or (ii)

\footnotetext{
${ }^{20}$ Nothing would change if the firm made the investment decision prior to the branding decision.

${ }^{21}$ Note that each firm's profit-maximizing investment strategy depends on consumers' beliefs but not on the other firms' investment decisions.
} 
$q_{n} \neq q_{o}$ and separate branding. Moreover, in equilibrium the branding decision has to be optimal given the (simultaneous) investment decision. ${ }^{22}$ A firm that can umbrella brand its new product with a good old product has a higher investment incentive than a single-product entrant because umbrella branding increases the value of the investment beyond what the entrant can expect. For a firm with a bad old product, the situation is exactly the reverse: the option to umbrella brand, chosen only if the investment is not made, increases the expected relative value of having two bad products.

Given the existence result for equilibria with perfect quality correlation in the baseline model (Proposition 1), it is not surprising that in the extended model there exist parameter values for which perfect quality correlation arises in equilibrium; in particular, this is again the case if failures are sufficiently strong indications of low quality, i.e., for $g$ close enough to 1 . Consider the following example:

Numerical Example For the parameter values $r=0.65, \delta=\beta=0.5, g=0.999999$, and $b=0.2$, there exists an equilibrium in which the firms' strategies are as follows: ${ }^{23}$

- If you are an entrant, invest in the quality of the new product if and only if $c<\widehat{c} \simeq 0.15$.

- If you are an incumbent with an old product of quality $q_{o}=g$, invest in the quality of the new product and umbrella brand if $c<\widehat{c}_{g} \simeq 0.27$; otherwise, do not invest and sell the two products under separate brands.

- If you are an incumbent with an old product of quality $q_{o}=b$, invest in the quality of the new product and sell under separate brands if $c<\widehat{c}_{b} \simeq 0.14$; otherwise, do not invest and sell the two products under an umbrella brand.

The corresponding equilibrium investment probabilities are $i_{g} \simeq 0.68, i \simeq 0.37$, and $i_{b} \simeq 0.35$. In expectation, the firm with the umbrella branding option invests more often than an entrant:

$$
r i_{g}+(1-r) i_{b} \simeq 0.56>i \simeq 0.37
$$

\subsection{Fit between Products}

A central theme in the empirical and experimental marketing literature on branding is that the fit between the old and the new product is a predictor of how correlated consumers' quality beliefs are.

\footnotetext{
${ }^{22}$ If, given the investment decision, firms had an incentive to opt for a different branding decision ex post, then their (joint investment and branding) strategy would clearly not be optimal.

${ }^{23}$ For these parameter values, there are no other pure strategy equilibria with feedback effects.
} 
The better the fit between products in terms of product characteristics, the higher the likelihood that umbrella branding permits a firm to leverage brand equity.

Formalizing this argument has proved difficult, however. Sappington and Wernerfelt (1985) model fit in a somewhat ad hoc way by assuming that incongruent extensions create "image costs", but overall the theoretical literature has largely ignored the question. The goal of this section is to propose a simple extension of the baseline model that takes a first step towards integrating the notion of fit into an information-based theory of branding. The focus will be on fit on the production side, as captured by perceived similarities in manufacturing in the experimental literature (see Bottomley and Holden 2001). ${ }^{24}$

Suppose that with probability $1-k \in[0,1]$ the multi-product firm is unable to observe the quality of the new product it is endowed with. In the baseline model, $k=1$. For $k<1$, the branding strategy is of the form $\left(x_{g g}, x_{g b}, x_{b g}, x_{b b}, y_{g}, y_{b}\right)$, where $y_{g}\left(y_{b}\right)$ is the probability of a brand extension if the new product is of unknown quality and the old product is good (bad). In a Bayesian equilibrium, consumers must take into account the possibility that the multi-product firm may not know quality. For example, $\mu_{g g}$ becomes

$$
\mu_{g g}^{k} \equiv \frac{r \gamma\left[k x_{g g}+(1-k) y_{g}\right]}{r\left(k\left[\gamma x_{g g}+(1-\gamma) x_{g b}\right]+(1-k) y_{g}\right)+(1-r)\left(k\left[\gamma x_{b g}+(1-\gamma) x_{b b}\right]+(1-k) y_{b}\right)}
$$

It is straightforward to see that for $k<1$ an equilibrium with perfect positive quality correlation, that is, of the form $(1,0,0,1,0,0)$, is less likely to exist than for $k=1$. In any perfect quality correlation equilibrium, it must be that $\Delta(g, g) \geq 0$ but $\Delta(g, b) \leq 0$. For $k<1$, an additional constraint is that the firm does not want to extend its brand to a new product of unknown quality. The expected average profit impact of umbrella branding in the latter case, let me denote it by $\Delta(g)$, is a weighted average of $\Delta(g, g)$ and $\Delta(g, b)$. Since $\Delta(g, g) \geq 0$, the equilibrium constraint that guarantees that products of unknown qualities are not sold under umbrella brands, i.e. $\Delta(g) \leq 0$, is at least as strict as the condition $\Delta(g, b) \leq 0$. Similarly, since it must be that $\Delta(b, b) \geq 0$, the condition $\Delta(b) \leq 0$ is at least as strict as the condition $\Delta(b, g) \leq 0$.

One interpretation of the parameter $k$ is that it measures the relatedness or fit between the old and the new product. Sellers are less able to evaluate the quality of new products that are far from their core competencies. Consumers, upon observing the new product's category and hence fit, anticipate the probability $k$ with which the seller knows the new product's quality. The above arguments then suggest that if the fit is bad $(k<1)$, an equilibrium with positive quality correlation

\footnotetext{
${ }^{24}$ The other main dimensions of fit used in the literature are demand subsitutability and demand complementarity.
} 
is less likely to exist.

\section{Concluding Remarks}

This paper shows that even if two products are unrelated from a technological point of view, the decision to sell them under the same brand name can credibly signal to consumers that the products' qualities are positively correlated. In such equilibria consumers correctly believe that the qualities of umbrella branded products are (likely or certain to be) identical, although consumers never fully learn qualities. Previous theories analyze umbrella branding as a guarantee of quality instead (Wernerfelt 1988; Choi 1998; Hakenes and Peitz 2008, 2009; Moorthy 2010), or assume perfect quality correlation for exogenous reasons (Cabral 2000).

Another key finding is that umbrella branding can lead to an hitherto unrecognized link between firms' incentives to invest in the quality of new products and the qualities of their existing products. Whenever umbrella branding signals positive quality correlation to consumers, the option to use an umbrella brand strengthens investment incentives for firms that already sell a high quality product, but weakens investment incentives for firms whose core product is of low quality.

My theory applies best to product categories where it is difficult for consumers to assess quality, such as high-tech products, expert services (lawyers, consultants,...), or drugs and some food categories. Brands play an important role as carriers of information about quality in such markets. ${ }^{25}$ In other product categories, such as fashion, a more important function of brands is probably that consumers can signal something about their type (income, taste, connoisseur knowledge) to others or to themselves by means of their brand choices. An umbrella brand can then be a profitable way to exploit the value of a brand that enjoys such a function (Pepall and Richards 2002).

Concerning future research, it seems very interesting, but difficult, to analyze the size limits of umbrella brands. Theories in which umbrella brands are a guarantee of high quality (Wernerfelt 1988; Choi 1998; Hakenes and Peitz 2008, 2009) imply that firms have nothing to lose from adding ever more high quality products to an umbrella brand. In a model as in this paper where consumers remain uncertain even after repeated consumption, on the other hand, including an additional product may be risky. If the failure of a small number of products in an umbrella brand is sufficient to convince consumers that all products are likely to be of low quality, i.e., if negative feedback effects are stronger

\footnotetext{
${ }^{25}$ See Tadelis (1999) and Hakenes and Peitz (2007) for models of name trading based on similar informational assumptions as my theory.
} 
than positive feedback effects, one would expect that at some point firms would not want to add any more products to an umbrella brand, even if all products are of high quality. 


\section{A Appendix}

Proof of Lemma 1: Let $i \neq-i \in\{o, n\}$. First note that since prices are linear in beliefs,

$$
E\left[w\left(\lambda_{\sigma_{i}}\left(\mu_{\sigma_{-i}}^{i}\right)\right)-w\left(\lambda_{\sigma_{i}}\left(\mu^{i}\right)\right) \mid q_{o}, q_{n}\right]>0
$$

is equivalent to

$$
E\left[\lambda_{\sigma_{i}}\left(\mu_{\sigma_{-i}}^{i}\right)-\lambda_{\sigma_{i}}\left(\mu^{i}\right) \mid q_{o}, q_{n}\right]>0
$$

As explained in section 3.1, $\lambda_{\sigma_{i}}\left(\mu^{i}\right)$ is the probability consumers would assign to product $i$ being good given only the following two pieces of information: first, the fact that product $i$ is umbrella branded, and second, its performance $\sigma_{i}$ :

$$
\lambda_{\sigma_{i}}\left(\mu^{i}\right)=\operatorname{Pr}\left\{q_{i}=g \mid \sigma_{i}, \text { umbrella branding }\right\} .
$$

The belief $\lambda_{\sigma_{i}}\left(\mu_{\sigma_{-i}}^{i}\right)$ is the probability consumers assign to product $i$ being good given not only $\sigma_{i}$ and the observation of an umbrella brand but also $\sigma_{-i}$ :

$$
\lambda_{\sigma_{i}}\left(\mu_{\sigma_{-i}}^{i}\right)=\operatorname{Pr}\left\{q_{i}=g \mid \sigma_{i}, \sigma_{-i}, \text { umbrella branding }\right\}
$$

Since $\sigma_{-i} \in\{S, F\}$, the following equality then directly follows from Bayes' rule:

$$
\begin{aligned}
\lambda_{\sigma_{i}}\left(\mu^{i}\right)= & \operatorname{Pr}\left\{\sigma_{-i}=S \mid \sigma_{i}, \text { umbrella branding }\right\} \lambda_{\sigma_{i}}\left(\mu_{S}^{i}\right) \\
& +\left(1-\operatorname{Pr}\left\{\sigma_{-i}=S \mid \sigma_{i}, \text { umbrella branding }\right\}\right) \lambda_{\sigma_{i}}\left(\mu_{F}^{i}\right) .
\end{aligned}
$$

As the belief that a product is good is a probability, any conditional probability assigned to a product's success must trivially lie between $b$ and $g$. Therefore: ${ }^{26}$

$$
\operatorname{Pr}\left\{\sigma_{-i}=S \mid \sigma_{i}, \text { umbrella branding }\right\} \in(b, g) .
$$

Now consider the case $q_{-i}=g$. Since $g>\operatorname{Pr}\left\{\sigma_{-i}=S \mid \sigma_{i}\right.$, umbrella branding $\}$, it is a straightforward implication of the equality in (10) that for any $\sigma_{i} \in\{S, F\}$ :

$$
g \lambda_{\sigma_{i}}\left(\mu_{S}^{i}\right)+(1-g) \lambda_{\sigma_{i}}\left(\mu_{F}^{i}\right)>\lambda_{\sigma_{i}}\left(\mu^{i}\right) \text { if and only if } \lambda_{\sigma_{i}}\left(\mu_{S}^{i}\right)>\lambda_{\sigma_{i}}\left(\mu_{F}^{i}\right) .
$$

As $\lambda_{\sigma_{i}}(\cdot)$ is strictly increasing, $\lambda_{\sigma_{i}}\left(\mu_{S}^{i}\right)>\lambda_{\sigma_{i}}\left(\mu_{F}^{i}\right)$ if and only if $\mu_{S}^{i}>\mu_{F}^{i}$, which is the case whenever successes have positive feedback effects, i.e., for $\rho>0$.

\footnotetext{
${ }^{26}$ The strict inclusion in the set $(b, g)$ follows from the simple fact that $\rho \neq 0$ is incompatible with umbrella branding fully revealing the quality of one (or both) of the products to consumers.
} 
The total "expected feedback effect" can be decomposed as follows:

$$
\begin{aligned}
& E\left[\lambda_{\sigma_{i}}\left(\mu_{\sigma_{-i}}^{i}\right)-\lambda_{\sigma_{i}}\left(\mu^{-i}\right) \mid q_{o}, q_{n}\right]=q_{i}\left[q_{-i} \lambda_{S}\left(\mu_{S}^{i}\right)+\left(1-q_{-i}\right) \lambda_{S}\left(\mu_{F}^{i}\right)-\lambda_{S}\left(\mu^{i}\right)\right] \\
& +\left(1-q_{i}\right)\left[q_{-i} \lambda_{F}\left(\mu_{S}^{i}\right)+\left(1-q_{-i}\right) \lambda_{F}\left(\mu_{F}^{i}\right)-\lambda_{F}\left(\mu^{i}\right)\right] .
\end{aligned}
$$

The finding in (12) directly implies that if quality correlation is positive, so that $\mu_{S}^{i}>\mu_{F}^{i}$, then both terms between square brackets are positive. Hence, if $\rho>0$, then

$$
E\left[\lambda_{\sigma_{i}}\left(\mu_{\sigma_{-i}}^{i}\right)-\lambda_{\sigma_{i}}\left(\mu^{-i}\right) \mid q_{i}, q_{-i}=g\right]>0
$$

If quality correlation is negative on the other hand, so that $\mu_{S}^{i}<\mu_{F}^{i}$, then

$$
E\left[\lambda_{\sigma_{i}}\left(\mu_{\sigma_{-i}}^{i}\right)-\lambda_{\sigma_{i}}\left(\mu^{-i}\right) \mid q_{i}, q_{-i}=g\right]<0
$$

Conversely, (10) and (11) imply that for $q_{-i}=b$ the inequalities in (13) and (14) are reversed. Q.E.D.

Proof of Proposition 1: The proof will proceed as follows. First I show that in the limit case $g=1$ (while all other parameters remain strictly between 0 and 1), a pure strategy equilibrium such that $\rho=1$ exists if and only if $\Delta_{1}>0, b \leq \bar{b}(r, \gamma, \beta)$, and $\underline{\delta}(r, \gamma, \beta, b) \leq \delta \leq \bar{\delta}(r, \gamma, \beta, b)$, where $\bar{b}(r, \gamma, \beta) \in(0,1)$, $\underline{\delta}(r, \gamma, \beta, b) \in(0,1)$ and $\bar{\delta}(r, \gamma, \beta, b) \in[\underline{\delta}(\cdot), 1)$. Since profits are smooth in $g$, the statement made in the proposition will follow from this result.

Suppose the firm's strategy is $\left(x_{g g}, x_{g b}, x_{b g}, x_{b b}\right)=(1,0,0,1)$. Then, $\mu^{o}=\mu^{n}, \mu_{S}^{o}=\mu_{S}^{n}$, and $\mu_{F}^{o}=\mu_{F}^{n}$. To simplify notations, I define $\mu \equiv \mu^{o}=\mu^{n}, \mu_{S} \equiv \mu_{S}^{o}=\mu_{S}^{n}$, and $\mu_{F} \equiv \mu_{F}^{o}=\mu_{F}^{n}$.

It is straightforward that if $g=1$, then a single failure suffices to convince consumers of bad quality:

$$
\lim _{g \rightarrow 1} \lambda_{F}(\widetilde{\mu})=0 \text { for any } \widetilde{\mu} \in[0,1) .
$$

Moreover, since consumers expect umbrella brands to always sell products of uniform quality, the failure of a single umbrella branded product suffices to convince consumers that both products are bad:

$$
\lim _{g \rightarrow 1} \mu_{F}=0
$$

Hence,

$$
\lim _{g \rightarrow 1} \lambda_{F}\left(\mu_{S}\right)=\lim _{g \rightarrow 1} \lambda_{S}\left(\mu_{F}\right)=\lim _{g \rightarrow 1} \lambda_{F}\left(\mu_{F}\right)=0 .
$$


These observations, and the linearity of $w(\cdot)$, imply that

$$
\begin{array}{cl}
\lim _{g \rightarrow 1} \Delta_{2}(S, S)=(1-b) & \left(\begin{array}{c}
(1-\beta)\left[\lim _{g \rightarrow 1} \lambda_{S}\left(\mu_{S}\right)-\lim _{g \rightarrow 1} \lambda_{S}(r)\right] \\
+\beta\left[\lim _{g \rightarrow 1} \lambda_{S}\left(\mu_{S}\right)-\lim _{g \rightarrow 1} \lambda_{S}(\gamma)\right]
\end{array}\right), \\
\lim _{g \rightarrow 1} \Delta_{2}(S, F)=(1-b)(1-\beta) & {\left[-\lim _{g \rightarrow 1} \lambda_{S}(r)\right]<0,} \\
\lim _{g \rightarrow 1} \Delta_{2}(F, S)=(1-b) \beta & {\left[-\lim _{g \rightarrow 1} \lambda_{S}(\gamma)\right]<0,} \\
\lim _{g \rightarrow 1} \Delta_{2}(F, F)=0 . &
\end{array}
$$

The expected marginal impacts of umbrella branding on second period profits are

$$
\begin{aligned}
\lim _{g \rightarrow 1} E\left[\Delta_{2}\left(\sigma_{o}, \sigma_{n}\right) \mid g, g\right]= & \lim _{g \rightarrow 1} \Delta_{2}(S S), \\
\lim _{g \rightarrow 1} E\left[\Delta_{2}\left(\sigma_{o}, \sigma_{n}\right) \mid g, b\right]= & b \lim _{g \rightarrow 1} \Delta_{2}(S S)+(1-b) \lim _{g \rightarrow 1} \Delta_{2}(S F), \\
\lim _{g \rightarrow 1} E\left[\Delta_{2}\left(\sigma_{o}, \sigma_{n}\right) \mid b, g\right]= & b \lim _{g \rightarrow 1} \Delta_{2}(S S)+(1-b) \lim _{g \rightarrow 1} \Delta_{2}(F S), \\
\lim _{g \rightarrow 1} E\left[\Delta_{2}\left(\sigma_{o}, \sigma_{n}\right) \mid b, b\right]= & b\left[b \lim _{g \rightarrow 1} \Delta_{2}(S S)+(1-b) \lim _{g \rightarrow 1} \Delta_{2}(S F)\right] \\
& +(1-b)\left[b \lim _{g \rightarrow 1} \Delta_{2}(F S)+(1-b) \lim _{g \rightarrow 1} \Delta_{2}(F F)\right] .
\end{aligned}
$$

An equilibrium with perfect quality correlation then exists if and only if the following four inequalities are satisfied, so that the branding strategy $(1,0,0,1)$ is indeed optimal:

$$
\begin{aligned}
& \lim _{g \rightarrow 1} \Delta(g, g)=(1-\delta) \Delta_{1}+\delta \lim _{g \rightarrow 1} E\left[\Delta_{2}\left(\sigma_{o}, \sigma_{n}\right) \mid g, g\right] \geq 0, \\
& \lim _{g \rightarrow 1} \Delta(g, b)=(1-\delta) \Delta_{1}+\delta \lim _{g \rightarrow 1} E\left[\Delta_{2}\left(\sigma_{o}, \sigma_{n}\right) \mid g, b\right] \leq 0, \\
& \lim _{g \rightarrow 1} \Delta(b, g)=(1-\delta) \Delta_{1}+\delta \lim _{g \rightarrow 1} E\left[\Delta_{2}\left(\sigma_{o}, \sigma_{n}\right) \mid b, g\right] \leq 0, \\
& \lim _{g \rightarrow 1} \Delta(b, b)=(1-\delta) \Delta_{1}+\delta \lim _{g \rightarrow 1} E\left[\Delta_{2}\left(\sigma_{o}, \sigma_{n}\right) \mid b, b\right] \geq 0 .
\end{aligned}
$$

To derive sufficient conditions under which (23) to (26) are indeed satisfied, I prove the following five statements step by step:

Step 1 In equilibrium, it must be that $\lim _{g \rightarrow 1} E\left[\Delta_{2}\left(\sigma_{o}, \sigma_{n}\right) \mid b, b\right]<0$ and $\Delta_{1}>0$.

Step 2 If $\Delta_{1}>0$, then equilibrium condition (23) is satisfied.

Step 3 If $\Delta_{1}>0$, then there exists a threshold $\bar{b}(r, \gamma, \beta) \in(0,1)$ such that

$$
\lim _{g \rightarrow 1} \Delta(b, b)>\max \left[\lim _{g \rightarrow 1} \Delta(g, b), \lim _{g \rightarrow 1} \Delta(b, g)\right]
$$

if and only if $b<\bar{b}(r, \gamma, \beta)$. 
Step 4 If $\Delta_{1}>0$ and $b<\bar{b}(r, \gamma, \beta)$, then there exist thresholds $\underline{\delta}(r, \gamma, \beta, b) \in(0,1)$ and $\bar{\delta}(r, \gamma, \beta, b) \in[\underline{\delta}(\cdot), 1)$ such that the equilibrium conditions (24), (25) and (26) are simultaneously satisfied if and only if $\delta \in[\underline{\delta}(r, \gamma, \beta, b), \bar{\delta}(r, \gamma, \beta, b)]$.

Step 1: For any $q_{o} \in\{b, g\}$,

$$
E\left[\Delta_{2}\left(\sigma_{o}, \sigma_{n}\right) \mid q_{o}, b\right]=q_{o} E\left[\Delta_{2}\left(S, \sigma_{n}\right) \mid q_{n}=b\right]+\left(1-q_{o}\right) E\left[\Delta_{2}\left(F, \sigma_{n}\right) \mid q_{n}=b\right]
$$

In any equilibrium with $\rho=1$, umbrella branding must be more profitable for a firm with two bad products than for a firm with a good old and bad new product. Clearly, for this to be true, it must be that

$$
E\left[\Delta_{2}\left(S, \sigma_{n}\right) \mid q_{n}=b\right] \leq E\left[\Delta_{2}\left(F, \sigma_{n}\right) \mid q_{n}=b\right]
$$

Now consider the limit case $g=1$. Since

$$
\lim _{g \rightarrow 1} E\left[\Delta_{2}\left(F, \sigma_{n}\right) \mid q_{n}=b\right]=b \underbrace{\lim _{g \rightarrow 1} \Delta_{2}(F S)}_{<0}+(1-b) \underbrace{\lim _{g \rightarrow 1} \Delta_{2}(F F)}_{=0}<0,
$$

(28) and (27) imply that

$$
\lim _{g \rightarrow 1} E\left[\Delta_{2}\left(\sigma_{o}, \sigma_{n}\right) \mid q_{o}, b\right]<0 \text { for } q_{o} \in\{g, b\} .
$$

For a $(b, b)$-firm to be willing to umbrella brand, i.e., for equilibrium condition (26) to hold for some discount factors, it is therefore necessary that

$$
\Delta_{1}>0 \Leftrightarrow \frac{r \gamma}{r \gamma+(1-r)(1-\gamma)}>(1-\beta) r+\beta \gamma
$$

It is straightforward to show that there exists a threshold $\underline{r}(\gamma, \beta) \in(0,1)$ such that $(29)$ is violated if $r<\underline{r}(\gamma, \beta)$ but holds for $r \in(\underline{r}(\gamma, \beta), 1)$.

Step 2: Given the strategy $(1,0,0,1)$,

$$
\Delta_{2}(S, S)=w\left(\lambda_{S}\left(\mu_{S}\right)\right)-(1-\beta) w\left(\lambda_{S}(r)\right)-\beta w\left(\lambda_{S}(\gamma)\right)
$$

which can be rewritten as

$$
\begin{aligned}
\frac{\Delta_{2}(S, S)}{(g-b)}= & {\left[\lambda_{S}\left(\mu_{S}\right)-\lambda_{S}(\mu)\right]+\left[\lambda_{S}(\mu)-\lambda_{S}((1-\beta) r+\beta \gamma)\right] } \\
& +\left[\lambda_{S}((1-\beta) r+\beta \gamma)-(1-\beta) \lambda_{S}(r)-\beta \lambda_{S}(\gamma)\right] .
\end{aligned}
$$

The first of the terms in this expression is positive because $\rho>0$ implies that $\mu_{S}>\mu$. The last term is positive because $\lambda_{S}(\cdot)$ is a concave function. Finally, the second term is positive whenever $\Delta_{1}>0$ (see (29)). Hence, if $\Delta_{1}>0$ then $\Delta_{2}(S, S)>0$. 
In the limit case $g=1$, a firm with two good products is certain to experience two successes. Hence, whenever $\Delta_{1}>0$, then also

$$
\lim _{g \rightarrow 1} \Delta(g, g)=(1-\delta) \Delta_{1}+\delta \underbrace{\lim _{g \rightarrow 1} \Delta_{2}(S, S)}_{>0}>0,
$$

i.e., equilibrium condition (23) is satisfied.

Step 3: I now show that there exists a threshold $\bar{b}(r, \gamma, \beta) \in(0,1)$ such that

$$
\lim _{g \rightarrow 1} \Delta(b, b)>\max \left[\lim _{g \rightarrow 1} \Delta(g, b), \lim _{g \rightarrow 1} \Delta(b, g)\right]
$$

if and only if $b<\bar{b}(r, \gamma, \beta)$. First, $\lim _{g \rightarrow 1} \Delta(b, b)>\lim _{g \rightarrow 1} \Delta(g, b)$ if and only if

$$
\lim _{g \rightarrow 1} E\left[\Delta_{2}\left(\sigma_{o}, \sigma_{n}\right) \mid b, b\right]>\lim _{g \rightarrow 1} E\left[\Delta_{2}\left(\sigma_{o}, \sigma_{n}\right) \mid g, b\right]
$$

Substituting for the expected profit differences and simplifying, this condition rewrites as

$$
b \lim _{g \rightarrow 1} \lambda_{S}\left(\mu_{S}\right)<(1-\beta) \lim _{g \rightarrow 1} \lambda_{S}(r)
$$

which is equivalent to

$$
b \frac{\mu}{\mu+(1-\mu) b^{2}}<(1-\beta) \frac{r}{r+(1-r) b},
$$

or

$$
K(b) \equiv b^{2}[\mu(1-\beta r)-(1-\beta) r]+b r \mu-(1-\beta) r \mu<0 .
$$

It is easy to see that $K(0)<0$. Moreover, $\Delta_{1}>0$ implies that $K(1)>0$. Since $K(b)$ describes a parabola, there then exists a unique $\bar{b}_{1}(r, \gamma, \beta) \in(0,1)$ such that $K(b)<0$ if and only if $b<\bar{b}_{1}(r, \gamma, \beta)$. Using the same line of reasoning, it is easy to show that there exists a $\bar{b}_{2}(r, \gamma, \beta) \in(0,1)$ such that

$$
\lim _{g \rightarrow 1} E\left[\Delta_{2}\left(\sigma_{o}, \sigma_{n}\right) \mid b, b\right]>\lim _{g \rightarrow 1} E\left[\Delta_{2}\left(\sigma_{o}, \sigma_{n}\right) \mid b, g\right]
$$

if and only if $b<\bar{b}_{2}(r, \gamma, \beta)$. Defining

$$
\bar{b}(r, \gamma, \beta) \equiv \min \left[\bar{b}_{1}(r, \gamma, \beta), \bar{b}_{2}(r, \gamma, \beta)\right],
$$

it follows that condition (30) is satisfied if and only if $b<\bar{b}(r, \gamma, \beta)$.

Step 4: Steps 1 and 3 establish that if $b<\bar{b}(r, \gamma, \beta)$, then

$$
\max \left[E\left[\Delta_{2}\left(\sigma_{o}, \sigma_{n}\right) \mid g, b\right], E\left[\Delta_{2}\left(\sigma_{o}, \sigma_{n}\right) \mid g, b\right]\right]<E\left[\Delta_{2}\left(\sigma_{o}, \sigma_{n}\right) \mid b, b\right]<0
$$


It is straightforward to see that if these inequalities hold and moreover $\Delta_{1}>0$, then there exists a non-empty range $[\underline{\delta}(r, \gamma, \beta, b), \bar{\delta}(r, \gamma, \beta, b)] \in(0,1)$ such that the equilibrium conditions $(24),(25)$ and (26) are simultaneously satisfied for any $\delta \in[\underline{\delta}(r, \gamma, \beta, b), \bar{\delta}(r, \gamma, \beta, b)] .{ }^{27}$ Moreover, for $\delta \in(\underline{\delta}(r, \gamma, \beta, b), \bar{\delta}(r, \gamma, \beta, b))$, the three equilibrium conditions (24), (25) and (26) are satisfied with strict inequalities.

To conclude note that, as long as $r, \gamma, b, \beta \in(0,1)$, the equilibrium profits from selling each of the products are smooth in $g .{ }^{28}$ The statement in the proposition then directly follows from the results established in steps 1 to 4 . Q.E.D.

Proof of Proposition 2: The first step is to show that there cannot be any equilibrium in which $\rho=-1$, i.e., $x_{g g}=x_{b b}=0$ but $x_{g b}, x_{b g}>0$. Such a strategy maximizes aggregate profits if $\Delta(b, g), \Delta(g, b) \geq 0$ but $\Delta(g, g), \Delta(b, b) \leq 0$. Hence, the following two conditions must hold in any equilibrium with $\rho=-1$ :

$$
\begin{aligned}
& \Delta(g, b) \geq \Delta(b, b), \\
& \Delta(b, g) \geq \Delta(b, b) .
\end{aligned}
$$

Since the first period impact of umbrella branding is independent of $\left(q_{o}, q_{n}\right)$, condition (33) is equivalent to

$$
E\left[\Delta_{2}\left(\sigma_{o}, \sigma_{n}\right) \mid g, b\right] \geq E\left[\Delta_{2}\left(\sigma_{o}, \sigma_{n}\right) \mid b, b\right]
$$

Condition (35) is indeed satisfied, i.e., the $(g, b)$-type has higher incentives to umbrella brand than the $(b, b)$-type, if and only if, given $q_{n}=b$, the expected impact of a success of the old product on the profit difference between umbrella and separate branding is positive:

$$
E\left[\Delta_{2}\left(S, \sigma_{n}\right) \mid q_{n}=b\right]-E\left[\Delta_{2}\left(F, \sigma_{n}\right) \mid q_{n}=b\right] \geq 0 .
$$

I now show that this condition is always violated if $\beta \geq \frac{1}{2}$. First, note that, since prices are linear in

\footnotetext{
${ }^{27}$ It is obvious that the range of $\delta$ for which an equilibrium exists is always included in $(0,1)$ here: since $\delta$ is the share of profits accruing to the second period, $\lim _{g \rightarrow 1} \Delta\left(q_{o}, q_{n}\right)$ can achieve any value between $\lim _{g \rightarrow 1} \Delta_{2}\left(q_{o}, q_{n}\right)$ and $\Delta_{1}$ by letting $\delta$ vary between 1 and 0 .

${ }^{28}$ If $r$ were equal to 1 , for example, then beliefs may not be smooth: While for $g=1$, it would not be clear what beliefs consumers should hold following a failure (of either one of the products), for $g$ almost equal to 1, they would always continue to believe that both products are good (even after observing two failures).
} 
beliefs, condition (36) can be rewritten as follows:

$$
\begin{aligned}
0 \leq b \quad & {[(1-\beta) \underbrace{\left[\lambda_{S}\left(\mu_{S}^{o}\right)-\lambda_{F}\left(\mu_{S}^{o}\right)\right]}_{>0 \text { (direct effect) }}+\beta \underbrace{\left[\lambda_{S}\left(\mu_{S}^{n}\right)-\lambda_{S}\left(\mu_{F}^{n}\right)\right]}_{<0 \text { (feedback effect) }}] } \\
& +(1-b)[(1-\beta) \underbrace{\left[\lambda_{S}\left(\mu_{F}^{o}\right)-\lambda_{F}\left(\mu_{F}^{o}\right)\right]}_{>0 \text { (direct effect) }}+\beta \underbrace{\left[\lambda_{F}\left(\mu_{S}^{n}\right)-\lambda_{F}\left(\mu_{F}^{n}\right)\right]}_{<0 \text { (feedback effect) }}] \\
& -(1-\beta)] \underbrace{\left[\lambda_{S}(r)-\lambda_{F}(r)\right]}_{>0 \text { (direct effect under separate branding) }}
\end{aligned}
$$

Both in the case of a success or of a failure of the new product, which occur with probabilities $b$ and $(1-b)$ respectively, the success of the old product has two different effects under umbrella branding: first, a positive direct effect on the belief consumers hold about the old product itself, and second, a negative feedback effect on consumers' belief about the new product. Under separate branding, the success of the old product only has a positive direct effect, whose size is independent of the new product's performance.

Next, note that in any equilibrium such that $\rho=-1$ consumers must be convinced that the umbrella brand sells one bad and one good product. This means that for any realization of performances, the probability consumers assign to the new product being good must be the "complement" of the probability they assign to the old product being good. Formally, for any $\left(\sigma_{o}, \sigma_{n}\right)$ :

$$
\lambda_{\sigma_{o}}\left(\mu_{\sigma_{n}}^{o}\right)+\lambda_{\sigma_{n}}\left(\mu_{\sigma_{o}}^{n}\right)=1
$$

From this it follows that (given the new product's performance) the positive (direct) effect a success of the old product has on the old product itself is exactly offset by its negative (feedback) effect on the new product: since for any $\sigma_{n}$,

$$
\lambda_{S}\left(\mu_{\sigma_{n}}^{o}\right)+\lambda_{\sigma_{n}}\left(\mu_{S}^{n}\right)=1=\lambda_{F}\left(\mu_{\sigma_{n}}^{o}\right)+\lambda_{\sigma_{n}}\left(\mu_{F}^{n}\right)
$$

it is always true that

$$
\left[\lambda_{S}\left(\mu_{\sigma_{n}}^{o}\right)-\lambda_{F}\left(\mu_{\sigma_{n}}^{o}\right)\right]=-\left[\lambda_{\sigma_{n}}\left(\mu_{S}^{n}\right)-\lambda_{\sigma_{n}}\left(\mu_{F}^{n}\right)\right]
$$

Substituting $-\left[\lambda_{S}\left(\mu_{\sigma_{n}}^{o}\right)-\lambda_{F}\left(\mu_{\sigma_{n}}^{o}\right)\right]$ for $\left[\lambda_{\sigma_{n}}\left(\mu_{S}^{n}\right)-\lambda_{\sigma_{n}}\left(\mu_{F}^{n}\right)\right]$, I can then simplify condition (37) to

$$
\begin{aligned}
0 \leq b(1-2 \beta) & \underbrace{\left[\lambda_{S}\left(\mu_{S}^{o}\right)-\lambda_{F}\left(\mu_{S}^{o}\right)\right]}_{>0}+(1-b)(1-2 \beta) \underbrace{\left[\lambda_{S}\left(\mu_{F}^{o}\right)-\lambda_{F}\left(\mu_{F}^{o}\right)\right]}_{>0} \\
& -(1-\beta) \underbrace{\left[\lambda_{S}(r)-\lambda_{F}(r)\right]}_{>0} .
\end{aligned}
$$


This condition is clearly violated for any $\beta \geq \frac{1}{2}$. First, if the firm attaches the same or more weight to the profits made on the new product, the negative feedback effect of a success of the old product outweighs its positive direct effect, hence the first two terms in (40) are negative. Second, successes always increase profits under separate branding, so that the last term in (40) is negative for any $\beta$.

Using the same line of reasoning, it is easy to show that for any $\beta \leq \frac{1}{2}$, firms with a bad old and a good new product would prefer separate to umbrella branding, i.e., condition (34) would be violated. I can conclude that the necessary conditions (33) and (34) are never simultaneously satisfied, and no equilibrium such that $\rho=-1$ exists.

The next step is to show that there cannot be any negative quality correlation equilibrium in which $x_{g g}=1$. In that case, $\rho<0$ only if $x_{b b}<x_{g b} x_{b g}$. It follows that both signaling effects are positive: $\mu^{o} \geq r$ and $\mu^{n} \geq \gamma$. Moreover, by Lemma 1, the total impact of feedback effects on expected profits is positive if both products are bad. Therefore, $\Delta(b, b)>0$, which implies that $x_{b b}=1$, a contradiction.

The final step is to show that there cannot be any equilibrium in which $x_{b b}=1$ either. If $\rho<0$ in equilibrium, then $\mu_{F}^{o}>\mu^{o}>\mu_{S}^{o}$ and $\mu_{F}^{n}>\mu^{n}>\mu_{S}^{n}$. In the following, I will show that $\mu_{F}^{o}<r$ and $\mu_{F}^{n}<\gamma$ if $x_{b b}=1$. From this, it will directly follow that for $x_{b b}=1$ umbrella branding is unprofitable, because it deteriorates the beliefs about both products in all circumstances. Consider

$$
\mu_{F}^{o}=\frac{r \gamma x_{g g}(1-g)+r(1-\gamma) x_{g b}(1-b)}{\left[r \gamma x_{g g}+(1-r) \gamma x_{b g}\right](1-g)+\left[r(1-\gamma) x_{g b}+(1-r)(1-\gamma) x_{b b}\right](1-b)} .
$$

It is easy to check that the belief $\mu_{F}^{o}$ is increasing in $x_{g g}$. For any $x_{b b}=1$, the correlation $\rho$ is negative if and only if $x_{g g}<x_{g b} x_{b g}$. Hence,

$$
\mu_{F}^{o}<\frac{r \gamma x_{g b} x_{b g}(1-g)+r(1-\gamma) x_{g b}(1-b)}{\left[r \gamma x_{g b} x_{b g}+(1-r) \gamma x_{b g}\right](1-g)+\left[r(1-\gamma) x_{g b}+(1-r)(1-\gamma) x_{b b}\right](1-b)}
$$

which simplifies to

$$
\mu_{F}^{o}<\frac{x_{g b} r}{x_{g b} r+(1-r)} \leq r
$$

Using the same line of reasoning, it is easy to show that if $\rho<0$ and $x_{b b}=1$, then

$$
\mu_{F}^{n}<\gamma
$$

Since $\rho<0$, it follows that also $\mu_{S}^{o}, \mu^{o}<r$ and $\mu_{S}^{n}, \mu^{n}<\gamma$. Therefore, $\Delta_{1}<0$ and $\Delta_{2}\left(\sigma_{o}, \sigma_{n}\right)<0$ for any $\left(\sigma_{o}, \sigma_{n}\right)$, so that $\Delta\left(q_{o}, q_{n}\right)<0$ for any $\left(q_{o}, q_{n}\right)$, which contradicts $\rho<0$. Q.E.D. 
Proof of Proposition 3: Suppose (in negation) that there is an equilibrium in which only firms with good old products extend their brands, i.e., $x_{b g}=x_{b b}=0$, but $x_{g g}>0$ and/or $x_{g b}>0$. Since even good products can fail (i.e., $g<1$ ), consumers then believe that the old product is good with probability 1 in both periods. Moreover, as $q_{o}$ is fully revealed, the old product's performance does not have any feedback effect on the new product. Aggregate profits under umbrella branding are therefore independent of the old product's true quality.

For any given $q_{n}$, if there is a difference between $\Delta\left(g, q_{n}\right)$ and $\Delta\left(b, q_{n}\right)$, then this must be due to a profits difference under separate branding. Since profits under separate branding are always lower the higher the number of bad products however, for any $q_{n} \in\{b, g\}$ :

$$
\Delta\left(b, q_{n}\right)>\Delta\left(g, q_{n}\right)
$$

This implies, however, that $x_{b g} \geq x_{g g}$ and $x_{b b} \geq x_{g b}$, which contradicts the initial assumption. By the same reasoning, it is easy to rule out equilibria in which umbrella branding fully reveals the new product's quality. Q.E.D.

Proof of Proposition 4: i) First consider the limit case $\beta=0$, in which the decision to umbrella brand is fully driven by its impact on the expected profits made from selling the core product. This expected profit impact can be decomposed into two terms corresponding to the signaling effect and the feedback effects on the old product, respectively. Moreover, the sign of the signaling effect is independent of qualities. The sign of the expected impact of the feedback effect on the old product depends on the quality of the new product however: by lemma 1 , it is positive if and only if $q_{n}=g$. Now consider any candidate equilibrium such that $\rho>0$. First, it is easy to see that the signaling effect must be positive in any such equilibrium. If it were negative, then for firms with a bad new product umbrella branding would reduce profits, since both signaling and feedback effects would reduce expected profits. If $x_{g b}=x_{b b}=0$ however, then umbrella branding does not signal any quality correlation. Therefore suppose that the signaling effect is positive. In that case, both signaling and feedback effects increase expected profits for firms with a good new product. This implies that $x_{g g}=x_{b g}=1$ in any such equilibrium. For the signaling effect to be indeed positive, it must then be that $x_{g b}>x_{b b}$. This leads to a contradiction of the initial assumption $\rho>0$, since - given that good new products are always umbrella branded - positive correlation would require that bad new products are more likely to be under an umbrella brand with other bad rather than good products.

Hence, for $\beta=0$, there does not exist any equilibrium such that $\rho>0$. Using the same approach, I can rule out all equilibria such that $\rho \neq 0$ for $\beta=1$ or $\beta=0$. Since profits are smooth in $\beta$, it follows from these results that equilibria with feedback effects do not exist for $\beta$ "too" close to 0 or 1 either. 
'Non-babbling' equilibria such that $\rho=0$ are also impossible. Since there are no feedback effects for $\rho=0$, whether firms want to umbrella brand or not will only depend on the signaling effect on one of the products, the sign of which is independent of qualities.

ii) If consumers' prior about one of the products is already perfectly accurate, then umbrella branding induces no feedback effects. Suppose, for example, that $r=1$. Then, the new product's performance cannot have any feedback effect on the old product under umbrella branding, since consumers remain convinced that the old product is good no matter what happens. Similarly, as the old product's performance has no direct effect on the belief about the old product itself, it cannot have any feedback effect on the new product either: $\mu^{n}=\mu_{S}^{n}=\mu_{F}^{n}\left(=\mu_{g g}\right)$. Umbrella branding has no signaling effect on the old product either, since consumers are already convinced of its quality. Branding incentives are hence driven by the signaling effect on the new product. The branding incentives of different types $\left(q_{o}, q_{n}\right)$ are thus fully aligned, and umbrella branding cannot credibly signal any quality information. As profits are smooth in $r$, it follows that for any strategy and values of the other parameters, there exists a threshold of $r$ above which the performance of the old product does not affect beliefs sufficiently for a non-babbling equilibrium to exist. I can use the same line of reasoning to rule out 'non-babbling' equilibria for $r$ close to 0 , or $\gamma$ close to 1 or to 0 .

iii) If the weight attached to future profits approaches 0 , then short term signaling effects completely drive the firm's decision to umbrella brand or not:

$$
\lim _{\delta \rightarrow 0} \Delta\left(q_{o}, q_{n}\right)=\Delta_{1} .
$$

In the limit, the incentives to umbrella brand are hence completely independent of qualities. By continuity, this implies that for $\delta$ sufficiently close to 0 , only babbling equilibria can exist. ${ }^{29}$

iv) If $b$ were equal to $g$, then performance would no longer yield any information about quality to consumers. Formally, this would mean that for any initial belief $\mu, \lambda_{S}(\mu)=\lambda_{F}(\mu)=\mu$. Hence,

$$
\lim _{b \rightarrow g} \Delta\left(q_{o}, q_{n}\right)=\Delta_{1},
$$

which is independent of $\left(q_{o}, q_{n}\right)$. It then follows from continuity that for $b$ sufficiently close to $g$, only 'babbling' equilibria can exist.

Q.E.D.

${ }^{29}$ Whenever $\Delta_{1} \neq 0$, the umbrella branding incentives of the different firm types are completely aligned for all $\delta$ below some strictly positive threshold. There may not exist any such strictly positive threshold of $\delta$ if $\Delta_{1}=0$ and one signaling effect is strictly positive, however. This case is neglected here because generically it does not occur. 
Proof of Proposition 5: Suppose that there exists at least one equilibrium that generates perfect positive quality correlation between umbrella branded products. In what follows, let me denote by $\pi^{U}\left(q_{o}, q_{n}\right)$ and $\pi^{S}\left(q_{o}, q_{n}\right)$, respectively, the mulit-product firm's expected aggregate profits gross of investment costs under umbrella branding and under separate branding, given $q_{o}$, and $q_{n}$ as determined by the investment decision. In line with previous notations, I use $\Delta\left(q_{o}, q_{n}\right)=\pi^{U}\left(q_{o}, q_{n}\right)-\pi^{S}\left(q_{o}, q_{n}\right)$. Note that in any equilibrium with perfect quality correlation, it must be that $\Delta(g, g), \Delta(b, b) \geq 0$ and $\Delta(g, b), \Delta(b, g) \leq 0$ : the branding decision must be optimal for any given investment decision, otherwise the firm's strategy (that determines investment and branding jointly) could not be optimal in the first place.

Investing in high quality is profitable for an entrant if and only if the expected increase in second-period profits exceeds the investment cost, i.e., whenever

$$
c \leq \Omega \equiv \beta \delta\left[w\left(\lambda_{S}(i)\right)-w\left(\lambda_{F}(i)\right)\right]
$$

Given my distributional assumptions, in equilibrium the following condition implicitly defines $i$ :

$$
i=\frac{\delta\left[w\left(\lambda_{S}(i)\right)-w\left(\lambda_{F}(i)\right)\right]}{g-b} .
$$

Clearly, $i=1$ cannot be a solution. $i=0$ solves (41), but cannot arise in an equilibrium with $\rho=1$ nonetheless. If $i=0$, then $\Delta(b, g)>\Delta(b, b)$ : (i) since consumers consider an individually branded new product to be bad no matter what, separate branding would give the same profit for the two quality profiles, but (ii) under umbrella branding the expected profit is evidently higher for the $(b, g)$-profile than for the $(b, b)$-profile. Hence, whenever $\Delta(b, g) \leq 0$, then $\Delta(b, b)<0$, which violates a necessary equilibrium condition. Therefore, in any equilibrium with $\rho=1$, it must be that $i \in(0,1) .{ }^{30}$

Next consider a multi-product firm with an old product of quality $q_{o}=g$. In any equilibrium with perfect quality correlation, this firm will either invest and umbrella brand, or alternatively not invest and use separate brands. Therefore, making the investment increases expected aggregate profits if and only if

$$
\begin{aligned}
\pi^{S}(g, b) & \leq \pi^{U}(g, g)-c \\
& \Leftrightarrow \\
c & \leq \underbrace{\left[\pi^{U}(g, g)-\pi^{S}(g, g)\right]}_{=\Delta(g, g)}+\underbrace{\pi^{S}(g, g)-\pi^{S}(g, b)}_{=\Omega}
\end{aligned}
$$

Since for $\rho=1$ to arise it is necessary that $\Delta(g, g) \geq 0$, we can conclude that $i_{g} \geq i$. Moreover, whenever $\Delta(g, g)>0$ (as is the case in such equilibria for $g$ close to 1 ), then $i_{g}>i$.

\footnotetext{
${ }^{30} \mathrm{~A}$ strictly positive solution of $(41)$ indeed exists if $\delta(g-b)^{2}>(1-b) b$, which is hence a necessary condition for an equilibrium with perfect quality correlation here.
} 
Now consider a multi-product firm whose old product is of quality $q_{o}=b$. In any equilibrium with $\rho=1$, this firm will either not invest and umbrella brand, or invest and opt for separate brands. Investing in the high quality if therefore profitable if and only if

$$
\begin{aligned}
\pi^{U}(b, b) & \leq \pi^{S}(b, g)-c \\
& \Leftrightarrow \\
c & \leq-\underbrace{\left[\pi^{U}(b, b)-\pi^{S}(b, b)\right]}_{=\Delta(b, b)}+\underbrace{\pi^{S}(b, g)-\pi^{S}(b, b)}_{=\Omega} .
\end{aligned}
$$

Since $\Delta(b, b) \geq 0$ is a necessary condition for an equilibrium with $\rho=1$, the right-hand side of this expression lies (weakly) below $\Omega$. Hence, $i^{b} \leq i$. Q.E.D. 


\section{References}

[1] Aaker, D. A. (2004). Brand Portfolio Strategy - Creating Relevance, Differentiation, Energy, Leverage, and Clarity. New York: Free Press.

[2] Aaker, D. A. and K. L. Keller (1990), "Consumer Evaluations of Brand Extensions," Journal of Marketing, 54(1), 27-41.

[3] Andersson, F. (2002), "Pooling Reputations," International Journal of Industrial Organization, $20(5), 715-730$.

[4] Bagwell, K. and M. H. Riordan (1991), "High and Declining Prices Signal Product Quality," American Economic Review, 81(1), 224-39.

[5] Balachander, S. and S. Ghose (2003), "Reciprocal Spillover Effects: A Strategic Benefit of Brand Extensions," Journal of Marketing, 67, 4-13.

[6] Bernheim, B. D. and M. D. Whinston (1990), "Multimarket Contact and Collusive Behavior," Rand Journal of Economics, 21(1), 1-26.

[7] Bottomley, P. A. and S. J. S. Holden (2001), "Do We Really Know How Consumers Evaluate Brand Extensions? Empirical Generalizations Based on Secondary Analysis of Eight Studies," Journal of Marketing Research, 38, 494-500.

[8] Cabral, L. M. B. (2000), "Stretching Firm and Brand Reputation," Rand Journal of Economics, $31(4), 658-673$.

[9] Cabral, L. M. B. (2009), "Umbrella Branding with Imperfect Observability and Moral Hazard," International Journal of Industrial Organization, 27(2), 206-213.

[10] Choi, J.P. (1998), "Brand Extension as Informational Leverage," The Review of Economic Studies, 65(4), 655-669.

[11] Claycamp, H. J. and L. E. Liddy (1969), "Prediction of New Product Performance: An Analytical Approach," Journal of Marketing Research, 6(4), 414-420.

[12] Erdem, T. (1998), "An Empirical Analysis of Umbrella Branding," Journal of Marketing Research, 35, 339-351. 
[13] Erdem, T. and B. Sun (2002), "An Empirical Investigation of the Spillover Effects of Advertising and Sales Promotions in Umbrella Branding," Journal of Marketing Research, 39, 408-420.

[14] Erdem, T. and R. S. Winer (1999), "Econometric Modeling of Competition: A Multi-category Choice-based Mapping Approach," Journal of Econometrics, 89, 159-175.

[15] Hakenes, H. and M. Peitz (2007), "Observable Reputation Trading," International Economic Review, 48, 693-730.

[16] Hakenes, H. and M. Peitz (2008), "Umbrella Branding and the Provision of Quality," International Journal of Industrial Organization, 26(2), 546-446.

[17] Hakenes, H. and M. Peitz (2009), "Umbrella Branding and External Certification," European Economic Review, 53(2), 186-196.

[18] John, D. R., Loken, B. and C. Joiner (1998), "The Negative Impact of Extensions: Can Flagship Products Be Diluted?" The Journal of Marketing, 62(1), 19-32.

[19] Kapferer, J.-N. (1997). Strategic Brand Management - Creating and Sustaining Brand Equity Long Term. London: Kogan Page.

[20] Klink, R. R. and D. C. Smith (2001), "Threats to the External Validity of Brand Extension Research," Journal of Marketing Research, 38(3), 326-335.

[21] Milgrom, P. and J. Roberts (1986), "Price and Advertising Signals of Product Quality," Journal of Political Economy, 94(4), 796-821.

[22] Montgomery, C. A. and B. Wernerfelt (1992), "Risk Reduction and Umbrella Branding," Journal of Business, 65(1), 31-50.

[23] Moorthy, S. (2010), "Can Brand Extension Signal Product Quality?" working paper, Rotman School of Management, University of Toronto.

[24] Pepall, L. M. and D. J. Richards (2002), "The Simple Economics of Brand Stretching," Journal of Business, 75, 535-552.

[25] Rasmusen, E. (2010), "Monopoly versus Competitive Leveraging of Reputation through Umbrella Pricing," working paper, Kelly School of Business, Indiana University. 
[26] Rotemberg, J. (2010), "Quality Provision, Expected Firm Altruism and Brand Extensions," NBER Working Paper 15635.

[27] Sappington, D. and B. Wernerfelt (1985), "To Brand or Not to Brand? A Theoretical and Empirical Question," Journal of Business, 58(3), 279-293.

[28] Smith, D. C. and C. W. Park (1992), "The Effects of Brand Extensions on Market Share and Advertising Efficiency," Journal of Marketing Research, 29, 296-313.

[29] Sullivan, M. (1990), "Measuring Image Spillovers in Umbrella-Branded Products," Journal of Business, 63(3), 309-329.

[30] Swaminathan, V., Fox, R. J., and S. K. Reddy (2001), "The Impact of Brand Extension Introduction on Choice," Journal of Marketing, 65(4), 1-15.

[31] Tadelis, S. (1999), "What's in a Name? Reputation as a Tradeable Asset," American Economic Review, 89(3), 548-563.

[32] Wernerfelt, B. (1988), "Umbrella Branding as a Signal of New Product Quality: An Example of Signaling by Posting a Bond," RAND Journal of Economics, 19(3), 458-466.

[33] Wolinsky, A. (1983), "Prices as Signals of Product Quality," Review of Economic Studies, 50, 647-658. 